OPEN ACCESS

Edited by:

Efrat Neter,

Ruppin Academic Center, Israel

Reviewed by:

James A. Green,

University of Limerick, Ireland

Radomir Masaryk,

Comenius University, Slovakia

*Correspondence:

Darko Jekauc

darko.jekauc@kit.edu

Specialty section:

This article was submitted to

Health Psychology,

a section of the journal

Frontiers in Psychology

Received: 06 November 2020

Accepted: 29 January 2021

Published: 04 March 2021

Citation:

Feil K, Allion S, Weyland S and Jekauc D (2021) A Systematic Review Examining the Relationship Between Habit and Physical Activity Behavior in Longitudinal Studies.

Front. Psychol. 12:626750 doi: 10.3389/fpsyg.2021.626750

\section{A Systematic Review Examining the Relationship Between Habit and Physical Activity Behavior in Longitudinal Studies}

\author{
Katharina Feil, Sarah Allion, Susanne Weyland and Darko Jekauc* \\ Department of Health Education and Sport Psychology, Institute of Sports and Sports Science, Karlsruhe Institute of \\ Technology, Karlsruhe, Germany
}

Purpose: To explain physical activity behavior, social-cognitive theories were most commonly used in the past. Besides conscious processes, the approach of dual processes additionally incorporates non-conscious regulatory processes into physical activity behavior theories. Habits are one of various non-conscious variables that can influence behavior and thus play an important role in terms of behavior change. The aim of this review was to examine the relationship between habit strength and physical activity behavior in longitudinal studies.

Methods: According to the PRISMA guidelines, a systematic search was conducted in three databases. Only peer-reviewed articles using a longitudinal study design were included. Both, habit and physical activity were measured at least once, and habit was related to physical activity behavior. Study quality was evaluated by assessment tools of the NHLBI.

Results: Of 3.382 identified publications between 2016 and 2019, fifteen studies with different study designs were included. Most studies supported that positive correlations between habit and physical activity exist. Some positive direct and indirect effects of habit on physical activity were detected and only a minority of studies showed the influence of physical activity on habit strength. Studies differentiating between instigation and execution habit found positive correlations and revealed instigation habit as a stronger predictor of physical activity. The quality of studies was rated as reasonable using assessment tools of the NHLBI.

Conclusion: This review revealed a bidirectional relationship between habit and physical activity. Whether habit predicts physical activity or vice versa is still unclear. The observation of habit influencing physical activity may be most appropriate in studies fostering physical activity maintenance while the influence of physical activity on habit may be reasonable in experimental studies with physical activity as intervention content to form a habit. Future investigations should differentiate between habit formation and physical activity maintenance studies depending on the research objective. Long-term 
study designs addressing the complexity of habitual behavior would be beneficial for establishing cue-behavior associations for the formation of habits. Furthermore, studies should differentiate between instigation and execution habit in order to investigate the influence of both variables on physical activity behavior independently.

Keywords: habit, physical activity, longitudinal, maintenance, review, automaticity

\section{INTRODUCTION}

Regular physical activity reduces the risk of premature mortality (Warburton and Bredin, 2017) and has a preventive effect on chronic diseases, such as coronary heart disease and diabetes mellitus (Reiner et al., 2013; Musich et al., 2017). Besides the physiological health benefits of physical activity, positive associations between physical activity and mental health were also found (White R. L. et al., 2017). However, the physical activity level of adults does not meet the international physical activity guidelines of the World Health Organization (WHO, 2010). A worldwide study found that $31 \%$ of adults are physically inactive with rates up to $43 \%$ in Western countries like America and east Mediterranean regions (Hallal et al., 2012).

In the past, physical activity behavior was most commonly explained by social-cognitive theories, such as the Theory of Planned Behavior (TPB) (Ajzen, 1991) or the Health Action Process Approach (HAPA) (Schwarzer, 2008). The intention towards the behavior is a fundamental component of these theories. Nevertheless, there remains an underestimated gap between intention and behavior. Constructs such as self-efficacy beliefs (Bandura, 2004) or action planning (Schwarzer, 2008) aim to bridge this intention-behavior gap, but evidence shows that only a small amount of physical activity behavior can be predicted by explicit processes (McEachan et al., 2011; Rhodes and Dickau, 2012).

Because conscious processes do not satisfactorily lead to health behavior changes, scientists suggest incorporating implicit regulatory processes into physical activity behavior theories (Marteau et al., 2012; Rhodes and Dickau, 2012; Sheeran et al., 2013; Strobach et al., 2020). A dual-process approach differentiates two processes as a basis for decision making toward a behavior (Evans and Stanovich, 2013). Type 1 is characterized as fast, nonconscious, and automatic, while type 2 is described as slow, conscious, and controlled. So far, physical activity behavior preceding from type 2 has mainly been the subject of investigations, but more recent studies referring to nonconscious processes have increasingly gained attention.

Habits are one of various non-conscious processes that can influence behavior (Lally and Gardner, 2013; Gardner, 2015; Rebar et al., 2016; Gardner and Lally, 2018). Gardner and Lally (2018, p. 209) defined habit as "a process whereby encountering a cue triggers an impulse to perform an action that has, through learning, become a learned response to the cue." Health behavior can become habitual, but authors argue that habit and behavior are not the same (Maddux, 1997). A framework was introduced by Gardner and Lally (2018) based on their previous work (Lally and Gardner, 2013) for understanding the habit formation process. According to their model, an intentional decision toward the behavior (stage 1) and a subsequent action initiation (stage 2) is necessary in order to show a behavior for the first time. Habit formation eventuates from repeating this behavior (stage 3a) and developing cue-behavior associations (stage 3b). Behavioral repetition is a central part of habit formation. Thus, as the habit forms, it influences subsequent behavior. As Gardner (2015) pointed out, the relationship between habit and behavior might be bidirectional and evolves over time. That behavior determines habit and habit determines behavior is crucial to understand the habit literature.

Complex health behaviors such as physical activity can be understood as a sequence of simple habitual actions (Maddux, 1997). Therefore, literature suggests a distinction between habitual initiation and habitual performance of the behavior. The decision toward physical activity behavior through unconsciously triggered impulses is called instigation habit whereas the execution habit is defined as habitually doing physical activity (Gardner, 2015; Gardner et al., 2020a). The performance of physical activity can become habitual through automatically executed sub-actions. While deciding to exercise builds the instigation habit ("Deciding to exercise... [... is something I do automatically]"), sub-actions like going to the gym or performing the exercise tasks at the gym are called execution habit ("Once I am exercising... [... is something I do automatically]") (Phillips and Gardner, 2016; Gardner et al., 2020a). In a current debate several authors critically discussed the definitions and relevance of instigation and execution habit toward physical activity behavior (Hagger, 2019, 2020; Gardner et al., 2020a). However, this discussion is still ongoing due to a lack of experimental studies focusing on these different constructs. Meanwhile, other scientists such as Kaushal et al. (2017a) extended the approach of instigation and execution habit, dividing exercise into two behavioral phases: preparatory and performance phase. The preparatory phase involves all behaviors until an individual reaches an exercise-ready state ("When I prepare to exercise... [... is something I do automatically]"). The performance phase starts when exercising begins ("When I exercise... [... is something I do automatically]") (Kaushal et al., 2017a). Kaushal et al. (2017a) assumed that the habituation of the preparation phase in physical activity behavior could be a more promising approach than focusing on the habituation of the performance phase because preparatory actions may be less complicated and shorter in duration than exercising itself.

Previous studies revealed that habit formation processes can affect health behaviors positively. In their meta-analysis, Gardner et al. (2011) found 23 habit-behavior relations across 21 data sets presenting a moderate-to-strong correlation between habit 
and physical activity behavior (fixed $r=0.43$, random $r=0.44$, $p<0.001)$. A recent systematic review by Rebar et al. (2016) supports these findings. Habit was positively associated with physical activity $(\mathrm{d}=0.67)$ which was confirmed in 13 out of 15 included studies.

Further, the role of habit as a moderator between intention and health behavior was investigated (Gardner, 2015; Rebar et al., 2016). A narrative review by Gardner (2015) showed that the predictive effect of intention on health behavior weakens when habit strength increases. Eleven included physical activity studies revealed mixed findings, but seven studies supported that an increasing habit debilitates the intentionbehavior relationship. Rebar et al. (2016) confirmed these findings and detected in most studies that intention-behavior associations are stronger for participants with lower habit strength compared to those with higher. However, Rebar et al. (2019) critically discussed in a current paper that this assumption is misleading due to linear modeling analysis. The authors observed the interrelatedness and typical asymmetrical distributions of intention and behavior using a simulated data set. They revealed similar moderating effects of high as well as low habits on the intention-behavior relationship. The previously moderating effects of habit may be based on statistical by-products of inappropriate model analyses. Therefore, Rebar et al. (2019) argued that strong conclusions about the moderating effect of habit should be reconsidered due to a high risk of misinterpreting tests. Additional to suitable moderation testing, intention-behavior profiles based on decisional intentions and subsequent behavior are recommended to enhance validity of findings (Rebar et al., 2019). Altogether, the moderating effect of habit is still unclear and the direct effect of habit on physical activity behavior has not been sufficiently investigated yet.

A small amount of observational and intervention studies in the narrative review by Gardner (2015) analyzed whether health behavior predicted habit strength. Here, estimated effect sizes must be interpreted with caution, because most studies tried to predict ongoing habits. To examine the effect of physical activity on habit, habit formation studies, where new habits emerge, would be more suitable (Gardner, 2015).

Current literature suggests that building an instigation habit is more valuable for the maintenance of behavior than an execution habit (Gardner and Lally, 2018). Instigation habit can be understood as "the direct activation of action" (Phillips and Gardner, 2016, p. 70) and therefore automatically generates the behavior performance (Phillips and Gardner, 2016). Thus, researchers assume behavior frequency is being regulated by instigation rather than execution habit (Gardner and Lally, 2018).

Further research with longer-term outcome measures will be essential so that the impact of non-conscious processes and health behavior maintenance can be observed (Rebar et al., 2016). Gardner (2015) recommended longitudinal study designs and within-person analyses to test causal influences on habit strength. The formation of habit within each participant should be included in statistical analyses, because between-subject effects only reflect the speed or peak of a groups' habit. Additionally, study quality would increase through multiple measurement occasions over a long time period with follow-up measures (Gardner, 2015; Rebar et al., 2016; Gardner and Lally, 2018).

The latest systematic review on habits and physical activity was conducted by Rebar et al. (2016) and revealed that implicit processes, such as habit, partially determine physical activity behavior. Recommendations for future studies were made and, therefore, we expect the latest studies to apply these guidelines. Studies published in the same time period might not have benefited from the results of the review by Rebar et al. (2016), but the claim for longitudinal study designs had already been made by Gardner et al. (2011). Consequently, the current review searched for longitudinal studies since 2016 to summarize the latest evidence in this field of research. The superior objective is to deepen the knowledge regarding the relationship between habit and physical activity behavior. Thus, the aim of this review was to examine the relationship between habit formation or habit strength and the acute level of physical activity behavior in longitudinal studies. Assuming that relevant studies conducted correlational analyses, our first hypothesis is formulated independently of the study design. Therefore, we expected (1) positive correlations between the variables habit and physical activity. Particularly, we hypothesized that (2a) higher habit strength leads to an increased level of physical activity and that $(2 \mathrm{~b})$ an increased level of physical activity leads to higher habit strength. Based on the latest research in this field we assumed that (3) the relationship between instigation habit and physical activity is stronger than the relationship between execution habit and physical activity.

\section{METHODS}

This systematic review was conducted according to the PRISMA guidelines (Liberati et al., 2009).

\section{Eligibility Criteria}

Studies meeting the following inclusion criteria were included in this review: (1) a measurement of physical activity with physical activity defined "as any bodily movement produced by skeletal muscles that results in energy expenditure" (WHO, 2020). Here, we also include intervention studies when the content of the intervention was clearly physical activity, although there was no statistical analysis testing the relationship between a concrete measurement of physical activity and habit. (2) A measurement of habit referring to physical activity specified as the self-reported habit index (SRHI) or the self-reported behavioral automaticity index (SRBAI) or a short version of these questionnaires. (3) Longitudinal study design with at least two measurement occasions. (4) Only published papers in peer-reviewed journals between April 2016 and November 2019 written in English or German. Exclusion criteria regarding the characteristics of the study population were not declared.

\section{Search}

The search was conducted on November 15, 2019, in the databases Web of Science, Pubmed, and Scopus. The constitution of the search term was based on the systematic review by Rebar et al. (2016), but was slightly adapted due to the focus on 
habit only and not on automatic associations or priming effects. Furthermore, we added a third part to the term to ensure a longitudinal study design. Our search terms consisted of the following three types of related terms:

1. Physical activity related terms: "physical activity" OR "exercise*” OR "sedentary" OR "walking”

2. Habit related terms: "SRHI" OR "habit" OR "habits" OR "habitual" OR "implicit"

3. Study design: "longitudinal" OR "maintenance" OR "within-subject" OR "with-in-person" OR "intervention"

At least one term within these three types had to be met in order to be included in the study. Furthermore, we screened reference lists and citations of eligible studies to identify additional relevant studies.

\section{Study Selection}

The search was executed by three independent reviewers with the data management system EndNote X9. In the first selection step, a screening of titles was carried out, followed by an inspection of eligibility criteria in the abstracts. Abstracts meeting the criteria were further examined by reading the full text of articles. Full texts were also read for studies with abstracts providing insufficient information about eligibility. Potential studies for inclusion in the review were scanned by all reviewers. Disagreements regarding inclusion were solved by discussion. Consensus was achieved in 100\% of the cases.

\section{Data Extraction}

We extracted the data from full-text articles, related publications, and supplementary material. The data was filled into an extraction form which contains source (authors, year of publication, country of origin), theory/model, study design (theory, measurement points, statistics), sample (setting, sample size, mean age), treatment (length of intervention, treatment, duration, frequency), outcome (measurements of physical activity and habit), and results. Only additional measurements and results related to the relationship between habit and physical activity were reported. Additional outcomes not relevant to the research question were not included in the data extraction.

\section{Quality Assessment}

To assess the risk of bias due to flaws in design and implementation of the studies, quality assessment tools of the National Heart, Lung, and Blood Institute (NHLBI, 2014) were used. According to the study design, tools for controlled intervention studies, observational cohort and cross-sectional studies, and before-after studies with no control group were applied. The study ratings incorporated selection bias across participants, study design, confounders, blinding of researchers and participants, data collection methods, and drop-outs. Quality evaluation occurred similarly for each tool, so that a unitary overall rating was possible, and comparability of the study quality was ensured. The global rating differentiated between poor, fair, and good study quality. Poor ratings indicated a significant risk of bias. Fair studies are susceptible to some bias, thus, these results should be considered as insufficiently valid. Least risk of bias is given in good-rated studies, whose results can be considered as valid. Three reviewers conducted the assessment independently. Discrepancies in the evaluation of items were marginal and immediately resolved by discussion in $100 \%$ of the cases.

\section{RESULTS}

\section{Study Selection}

After removing duplicates, a total of 3.382 studies were identified and 191 studies remained after screening titles. Abstract screening revealed 87 eligible full-text articles for full-text screening. During full-text reading, 64 studies were excluded as they did not meet the inclusion criteria. An additional five studies were eliminated because the results did not answer the research question of this review. These included a validity study of another measurement of habit (Boiché et al., 2016), a feasibility study with insufficient statistical results (Ashe et al., 2019), and studies not reporting habit as an individual variable and its relationship to physical activity (Phillips et al., 2016; Duan et al., 2017; Howlett et al., 2019). One study was excluded, because habit did not refer directly to physical activity but to wearing a Fitbit (Ellingson et al., 2019). Furthermore, two studies did not meet the inclusion criterion of connecting habit to physical activity through either a statistical analysis or using physical activity as the content of intervention (Hamilton et al., 2019; Wallmann-Sperlich et al., 2019). In total, 15 studies were included in this systematic review (see Figure 1).

\section{Study Characteristics}

Country, study design, background theories, outcome measurement tools, and statistical analysis of included studies are shown in Table $\mathbf{1 .}$

Target populations in the studies were adults (Schwarzer et al., 2017; Bird et al., 2018), university students and staff (Allom et al., 2016; Phillips and Gardner, 2016; Pfeffer and Strobach, 2018), cardio-vascular patients (Fournier et al., 2018), gym members (Kaushal et al., 2017a, 2018), older adults (Arnautovska et al., 2016; van Bree et al., 2016, 2017; White I. et al., 2017), office employees (Fournier et al., 2016), pregnant women (Mullan et al., 2016), and parents (Rhodes et al., 2019b). The inquiry period ranged from 1 week (Allom et al., 2016; Mullan et al., 2016; Pfeffer and Strobach, 2018; Rhodes et al., 2019b) to 2 years (Bird et al., 2018). The number of post-baseline measurement occasions varied between 1 (Allom et al., 2016; Arnautovska et al., 2016; Phillips and Gardner, 2016; Kaushal et al., 2017a, 2018; Bird et al., 2018; Pfeffer and Strobach, 2018) and 4 years (Fournier et al., 2018). Moreover, weekly measurements were applied only in two studies, one reporting habit (Fournier et al., 2016) and one reporting physical activity (Rhodes et al., 2019b). In intervention studies, the length of treatment differed between eight (Kaushal et al., 2018) to 28 weeks (Fournier et al., 2016). Besides widely known cognitive theories like TPB and dual-process approaches, very few studies named a concrete habit theory like the habit model by Lally and Gardner (2013). Most studies focused on the construct of habit as their theoretical basis and some of them did not refer to an existing theory by name (no theory). 


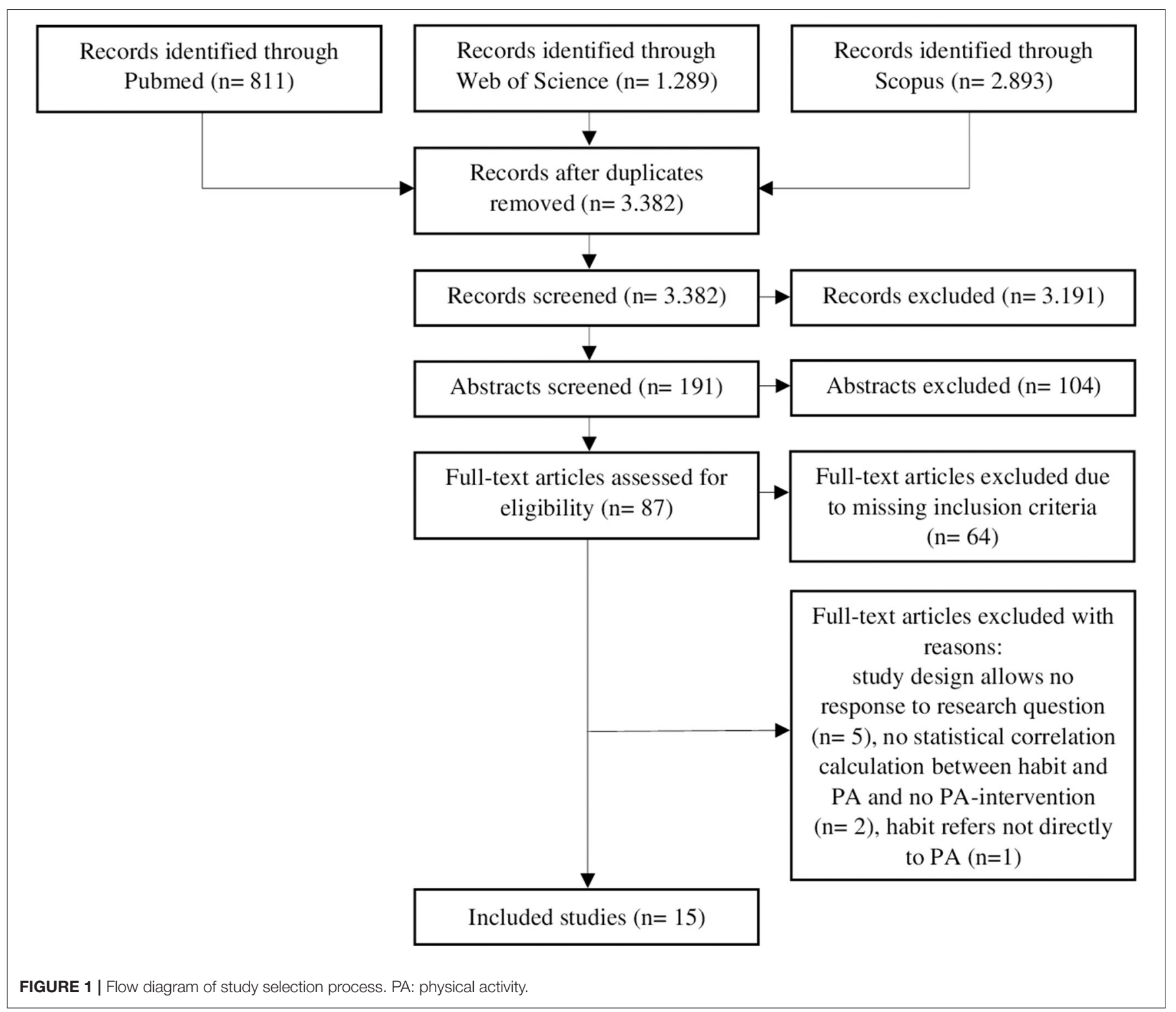

In addition to the background theories, four studies described further theoretical approaches to implement the study procedure. In this case, theories were applied to examine the adaptability of the constructs or to facilitate the implementation process of an intervention. These theories were an extended version of the TPB (Bird et al., 2018), a dual-process approach (Kaushal et al., 2017a), and the Multi-Process Action Control (M-PAC) (Kaushal et al., 2018; Rhodes et al., 2019b).

\section{Quality Assessment}

A total of five studies were rated as poor (Allom et al., 2016; Arnautovska et al., 2016; Mullan et al., 2016; Bird et al., 2018; Kaushal et al., 2018), as fair (van Bree et al., 2016, 2017; Kaushal et al., 2017a; Schwarzer et al., 2017; White I. et al., 2017), and as good quality (Fournier et al., 2016, 2018;
Phillips and Gardner, 2016; Pfeffer and Strobach, 2018; Rhodes et al., 2019b). When no power analysis was conducted (Allom et al., 2016; Arnautovska et al., 2016; Mullan et al., 2016; Bird et al., 2018) and no repeated measurement of exposure and outcome was operated (Allom et al., 2016; Arnautovska et al., 2016; Mullan et al., 2016), quality was rated as poor. Additionally, in one poor-rated study, blinding was not reported and data of intervention participants who did not attend were used for analysis in the control group (Kaushal et al., 2018). Also, poor quality was assessed for one study using only a single item of the SRHI and in which the timeframe was not appropriate for only two measurement occasions (Bird et al., 2018). Another reason for poor quality was that the outcome measures were not reported as valid and reliable (Mullan et al., 2016). The rating of each item can be found in the Supplementary Material. 
TABLE 1 | Study characteristics.

\begin{tabular}{|c|c|}
\hline Study characteristics & Numbe \\
\hline \multicolumn{2}{|l|}{ Country } \\
\hline Europe & 8 \\
\hline North America & 4 \\
\hline Australia & 3 \\
\hline \multicolumn{2}{|l|}{ Study design } \\
\hline Longitudinal observational design & 9 \\
\hline Longitudinal two-arm intervention design & 3 \\
\hline $\mathrm{RCT}$ & 3 \\
\hline \multicolumn{2}{|l|}{ Theories } \\
\hline Social-cognitive theories (TPB, HAPA, strength model of self-control) & 6 \\
\hline Habit theories & 3 \\
\hline Dual-process approach (RIM, dual-process model) & 1 \\
\hline No theory & 5 \\
\hline \multicolumn{2}{|l|}{ Measurement of habit } \\
\hline SRBAI & 11 \\
\hline $\mathrm{SRHI}$ & 2 \\
\hline Items of SRHI and SRBAI & 2 \\
\hline Single-item SRHI & 2 \\
\hline \multicolumn{2}{|l|}{ Measurement of physical activity } \\
\hline Questionnaire & 8 \\
\hline Single items & 7 \\
\hline Accelerometer & 2 \\
\hline Electronic daily diary report & 1 \\
\hline \multicolumn{2}{|l|}{ Statistical analysis } \\
\hline Correlation & 12 \\
\hline Regression & 7 \\
\hline Structural equation model & 4 \\
\hline Mixed model/ general linear model & 2 \\
\hline Mediation analysis & 1 \\
\hline ANOVA & 1 \\
\hline
\end{tabular}

\section{Relationship Between Habit and Physical Activity \\ Hypothesis 1: Positive Correlations Between the Variables Habit and Physical Activity}

Nine studies examined correlations between habit and physical activity through bivariate correlation analysis and eight studies confirmed the first hypothesis of a positive correlation (Allom et al., 2016; Arnautovska et al., 2016; Mullan et al., 2016; Phillips and Gardner, 2016; van Bree et al., 2016, 2017; Kaushal et al., 2017a, 2018; Schwarzer et al., 2017; Pfeffer and Strobach, 2018; Rhodes et al., 2019b). The highest positive correlation was revealed by Mullan et al. (2016) $(r=0.62, p<0.01)$ and the lowest by Schwarzer et al. (2017) $(r=0.16, p<0.01)$. Only White I. et al. (2017) reported no significant relation between the two variables; no study reported negative correlations.

\section{Hypothesis 2a: Higher Habit Strength Leads to an Increased Level of Physical Activity}

The second hypothesis proposes that habit formation leads to an increase in physical activity. Results can be distinguished between direct and indirect prediction of physical activity. Two studies investigated the direct effects of habit on physical activity (Arnautovska et al., 2016; Rhodes et al., 2019b). Arnautovska et al. (2016) revealed that habit influences physical activity directly $(\beta=0.24, p<0.01)$ through a structural equation model. Rhodes et al. (2019b) showed that habit was a predictor of physical activity in successful intenders compared to unsuccessful intenders using accelerometry $(\mathrm{OR}=1.99, p<0.01)$ and selfreported measurements $(\mathrm{OR}=1.60-2.08, p<0.01-0.05)$.

Another five studies detected indirect effects of habit on physical activity (Allom et al., 2016; Mullan et al., 2016; Schwarzer et al., 2017; Bird et al., 2018; Pfeffer and Strobach, 2018). Different regression models including psychological and demographic variables were applied to explain physical activity behavior. For example, Pfeffer and Strobach (2018) investigated the association between self-control and physical activity, and assumed that habit moderates or mediates this relationship in university students. The authors conducted this study in a laboratory setting and reported habit as a moderator $(\beta=0.23, p<0.01)$ and mediator $(ß=0.28, p=0.01)$, predicting physical activity in a model with age, sex, and self-control. Beyond that, the interaction effect between habit and self-control functioned as a moderator toward physical activity $(~(\beta=0.19, p=0.028)$. Schwarzer et al. (2017) used a digital intervention in European countries to improve physical activity in adults. A structural equation model was applied to examine psychological variables such as motivation, planning, self-monitoring, habit, and physical activity, which were placed in a sequential manner. Influenced by these variables, habit was found as a predictor of physical activity in men ( $\beta$ $=0.17, p<0.01)$ and women $(\beta=0.23, p<0.01)$. Bird et al. (2018) used a sample from a project study focusing on purposebuilt infrastructure. They aimed to improve walking and cycling routes in specific regions of the UK. The effect of a high habit on physical activity was analyzed after 1 or 2 years, applying an extended model of the TPB. A high habit was associated with walking and cycling for transport or recreational use. Results show positive effects on walking and cycling for transport with RRR varying between $2.24(p<0.01)$ and $3.33(p<0.05)$, but inconclusive findings for recreational use. In fact, an increase as well as a decrease in walking for recreation was found. In most cases, the cohort group measured after 2 years yielded a higher effect of habit on physical activity. Allom et al. (2016) looked at the importance of intentions and habits of first generation students transitioning to college and how these life-changes influenced physical activity behavior. Habit was a significant predictor of physical activity $(B=0.36, p<0.01)$ in a hierarchical regression analysis. Allom et al. (2016) used the same statistical procedure and revealed similar results $(B=0.33, p<0.01)$ in pregnant women.

\section{Hypothesis 2b: Increased Level of Physical Activity Leads to Higher Habit Strength}

The influence of physical activity on habit strength in two different sample sizes from previous studies was examined in the study of van Bree et al. (2016). Physical activity was used as a mediator between intention and habit. A regression analysis revealed an effect of physical activity on habit in study one (âbcs 
$=0.18, p<0.01$ ) as well as in study two (âbcs $=0.21, p<0.01$ ). The standardized indirect effect was expressed through âbcs and showed medium to large effects $(0.01=$ small, $0.09=$ medium, $0.25=$ large).

Two intervention studies showed that habit significantly increased over time throughout all intervention groups (Fournier et al., 2016, 2018). In Fournier et al. (2016), the first intervention group received a physical activity program and habit promoting cues, while the second group only received a physical activity intervention. Therefore, physical activity might be the central intervention content that leads to a higher level of habit in these cases. Fournier et al. (2016) yielded a higher habit strength in the first group which received additional cues for habit formation $(\mathrm{B}=0.05, p<0.01)$ compared to the second group performing only a physical activity program $(B=0.02, p=0.02)$. Moreover, the first intervention group reached a significantly higher level of physical activity at follow-up $\left[\mathrm{t}_{(14)}=2.20, p=\right.$ $0.04]$ than the second intervention group $\left[\mathrm{t}_{(7)}=1.28, p=0.24\right]$. These findings support the assumption that habit formation interventions lead to a higher level of physical activity and would therefore support hypothesis $2 \mathrm{a}$ as well. However, in Fournier et al. (2018), subgroups did not differ in habit or physical activity, and physical activity did not significantly change over time.

In another study, van Bree et al. (2017) applied a crosslagged panel design to investigate whether habit mediates the relationship between prior and later physical activity (physical activity-habit-physical activity) and vice versa (habit-physical activity-habit). Two different sample sizes from previous studies were used to adapt the design. Study 1 revealed a significant mediation effect for the path habit-physical activity-habit (âbcs $=0.01, p=0.006$ ), while the path physical activity-habitphysical activity showed only marginal significance. In study 2 , contrary findings were reported with a significant mediation effect for the path physical activity-habit-physical activity (âbcs $=0.03, p<0.01$ ) while the path habit-physical activity-habit was not significant.

\section{Hypothesis 3: Relationship Between Instigation Habit and Physical Activity Is Stronger Than the Relationship Between Execution Habit and Physical Activity}

Only one study investigated instigation and execution habit separately (Phillips and Gardner, 2016). The authors revealed correlations between instigation habit and physical activity at different occasions ( $r$-values between $r=0.32-56, p<0.01$ ), whereas lower correlations were found between execution habit and physical activity ( $r$-values between $r=0.22-0.41, p<$ 0.05 and $p<0.01$ ). Multiple regression analysis yielded only instigation habit as a predictor of physical activity at $\mathrm{t} 2$ (daily diary report: $\beta=0.31, \mathrm{t}_{(3,108)}=2.56, p=0.01$; physical activity 1 item: $\left.\beta=0.39, \mathrm{t}_{(3,107)}=3.16, p<0.01\right)$. Furthermore, Phillips and Gardner (2016) examined whether the change of physical activity is associated with change in instigation habit. Participants with a high physical activity level at baseline and a decrease over time (high/low group) showed a negative change in instigation habit at $\mathrm{t} 1$ (slope $=-0.46, p=0.02$ ). The positive change in instigation habit for participants increasing their physical activity level from low to high was not significant ( $l$ lope $=0.21, p=0.22$ ).

Kaushal et al. (2017a, 2018) focused on preparatory and performance habits of physical activity in gym members as an extended approach to Phillips and Gardner (2016). Both studies revealed correlations between preparatory habit and physical activity and performance habit and physical activity. Preparatory habit showed only marginally higher values $(r=0.22-25, p<$ $0.01)$ compared to performance habit $(r=0.20-23, p<0.05$ and $p=0.01)$. Structural equation models yielded preparatory habit as a significant predictor for physical activity $(B=0.20, p$ $=0.03)$ and change in physical activity $(\beta=0.18-20, p=0.04)$ (Kaushal et al., 2017a). No significant effect of performance habit on physical activity was found (Kaushal et al., 2017a, 2018).

A detailed data extraction of the studies and their results are shown in Table 2.

\section{DISCUSSION}

The purpose of this review was to investigate the relationship between habit and physical activity behavior in longitudinal studies. Our first hypothesis did not focus on the longitudinal study design, but nevertheless the majority of studies supported that positive correlations between habit and physical activity exist. Furthermore, our second hypothesis was that higher habit strength leads to an increased level of physical activity and vice versa. Positive direct effects of habit on physical activity were detected in only two studies. Several studies presented indirect effect sizes, which cannot be compared to each other due to the influence of several psychological variables on the relationship of habit and physical activity in different model constellations. Therefore, a confident confirmation for this direction of effect is not possible. Only one study revealed that physical activity influenced habit strength and two other studies showed the effect of physical activity interventions to strengthen habit. Because of the insufficient number of presented studies, the hypothesis cannot be confirmed satisfactorily. One study applied a cross-lagged panel design to answer both directions of effect and reported inconclusive results. A distinction between instigation or preparatory and execution or performance habit was conducted in three studies, which showed positive correlations for both habit variables and physical activity. These studies supported the third hypothesis, namely that the relationship between instigation or preparatory habit and physical activity is stronger than that between execution or performance habit and physical activity.

\section{Theoretical Background Considerations}

Studies based on cognitive theories added habit as a nonconscious construct to explain physical activity behavior. Similar to dual-process approaches (Evans, 2008; Evans and Stanovich, 2013; Presseau et al., 2014), both conscious and non-conscious processes are relevant to force behavior change. Therefore, it is advisable to combine both approaches as a holistic theoretical foundation. To realize this in future research, the framework M-PAC by Rhodes (2017) could be helpful for intervention studies to focus on habit formation and 
TABLE 2 | Data extraction of included studies.

\begin{tabular}{|c|c|c|c|c|c|c|}
\hline $\begin{array}{l}\text { References } \\
\text { Country of } \\
\text { origin }\end{array}$ & Theory/model & $\begin{array}{l}\text { Study design (measurement } \\
\text { occasions, statistics) }\end{array}$ & $\begin{array}{l}\text { Sample (final sample } \\
\text { size, gender proportion, } \\
\text { mean age) }\end{array}$ & $\begin{array}{l}\text { Treatment (content, length, } \\
\text { duration, frequency) }\end{array}$ & $\begin{array}{l}\text { Outcome (measurements } \\
\text { of habit and PA) }\end{array}$ & Results \\
\hline $\begin{array}{l}\text { Allom et al. (2016) } \\
\text { Australia }\end{array}$ & TPB & $\begin{array}{l}\text { Longitudinal observational design } \\
\text { Baseline (SRHI) } \\
\text { follow-up (PA items, } 1 \text { week) } \\
\text { Bivariate correlation } \\
\text { Multiple regression analysis }\end{array}$ & $\begin{array}{l}\text { College students } \\
N=101 \\
M=19.6 \pm 4.88\end{array}$ & No treatment & $\begin{array}{l}\text { Habit: SRHI } \\
\text { PA: } 2 \text { single-items } \\
\text { "In the last week, to what } \\
\text { extent did you do regular } \\
\text { PA?" } \\
\text { "How often in the last week } \\
\text { did you do regular PA?" }\end{array}$ & $\begin{array}{l}\text { Bivariate correlation between habit and PA }(r \\
=0.61, p<0.01) \\
\text { Multiple regression analysis: habit was a sig. } \\
\text { predictor of PA ( } \beta=0.36, p<0.01 \text { ) (model } \\
\text { with sex, intention, PBC, intention } \times \text { habit) }\end{array}$ \\
\hline $\begin{array}{l}\text { Arnautovska et al. } \\
\text { (2016) } \\
\text { Australia }\end{array}$ & $\begin{array}{l}\text { TPB, HAPA, RIM, } \\
\text { Dual-process model } \\
\text { (Presseau et al., } \\
\text { 2014) }\end{array}$ & $\begin{array}{l}\text { Longitudinal observational design } \\
\text { Baseline (SRBAl) } \\
\text { t1 (PA items, } 2 \text { weeks) } \\
\text { Bivariate correlation, Structural } \\
\text { equation model }\end{array}$ & $\begin{array}{l}\text { Older adults } \\
\begin{array}{l}N=165(66.7 \% \text { female }) \\
M=73.8 \pm 7.0\end{array}\end{array}$ & No treatment & $\begin{array}{l}\text { Habit: SRBAl } \\
\text { PA: } 3 \text { single-items } \\
\text { "On how many days in the } \\
\text { past week (past } 7 \text { days) } \\
\text { have you engaged in at } \\
\text { least } 30 \text { min of at least } \\
\text { moderate-intensity PA?" } \\
\text { "In the previous week, how } \\
\text { often did you engage in } \\
\text { regular PA?" } \\
\text { "In the previous week, to } \\
\text { what extent did you engage } \\
\text { in regular PA?" }\end{array}$ & $\begin{array}{l}\text { Bivariate correlation between habit strength } \\
\text { at baseline and PA at } t 2(r=0.51, p<0.01) \\
\text { Structural equation model: habit strength } \\
\text { sig. predicts PA ( } B=0.24, p<0.01)\end{array}$ \\
\hline $\begin{array}{l}\text { Bird et al. (2018) } \\
\text { UK }\end{array}$ & TPB, eTPB & $\begin{array}{l}\text { Longitudinal observational cohort } \\
\text { design } \\
\text { Baseline } 2010 \text { (SRHI } 1 \text { item, PA } \\
\text { self-report) } \\
\text { Cohort (1) follow-up in } 2011 \text { (SRHI } \\
1 \text { item, PA self-report, } 1 \text { year) } \\
\text { Cohort (2) follow-up in } 2012 \text { (SRHI } \\
1 \text { item, PA self-report, } 2 \text { years) } \\
\text { Regression analysis }\end{array}$ & $\begin{array}{l}\text { Adults } \\
n=1.796 \\
(54.5 \% \text { female) } \\
n=1.465 \\
\text { ( } 56.7 \% \text { female) } \\
\text { No total } M_{\text {age }} \\
\text { (for details see Ogilvie et al. } \\
\text { (2011, 2012) }\end{array}$ & $\begin{array}{l}\text { No treatment } \\
\text { Data from the iConnect study } \\
\text { (Ogilvie et al., 2012) used to } \\
\text { examine psychological } \\
\text { predictors of change in walking/ } \\
\text { cycling for recreation using an } \\
\text { extended version of TPB }\end{array}$ & $\begin{array}{l}\text { Habit: SRHI } 1 \text { item (walking } \\
\text { /cycling for recreation } \\
\text { (leisure, health, fitness)/ for } \\
\text { transport (to get to places) } \\
\text { is something I do } \\
\text { automatically without really } \\
\text { thinking about it) } \\
\text { PA: self-report based on } \\
\text { IPAQ (min/week) }\end{array}$ & $\begin{array}{l}\text { Regression analysis (model } 3 \text { with PBC, } \\
\text { intention, habit, visibility and controlled } \\
\text { variables): } \\
\text { Associations between high habit and } \\
\text { - increase in walking for transport in (2) (RRR } \\
=2.24(1.41-3.57), p<0.01) \\
\text { - increase in walking for recreation in (1) [RRR } \\
=1.89(1.29-2.77), p<0.01] \text { and (2) [RRR } \\
=2.36(1.53-3.65), p<0.01] \\
\text { - decrease in walking for recreation in (1) } \\
{[R R R=1.67(1.10-2.53), p<0.05) \text { and (2) }} \\
{[R R R=2.43(1.52-3.87), p<0.001]} \\
\text { - increase in cycling for transport in (1) [RRR } \\
=2.89(1.37-6.06), p<0.01] \text { and (2) } \\
\text { [RRR }=3.33(1.31-8.45), p<0.05] \\
\text { Association between habit and } \\
\text { increase/decrease in cycling for recreation } \\
\text { in (1) and (2) n.s. }\end{array}$ \\
\hline $\begin{array}{l}\text { Fournier et al. } \\
\text { (2016) } \\
\text { France }\end{array}$ & - & $\begin{array}{l}\text { Longitudinal two-arm intervention } \\
\text { design } \\
\text { t1-t28 (SRBAl, weekly) } \\
\text { follow-up (IPAQ, } 19 \text { months) } \\
\text { Mixed model, General linear model }\end{array}$ & $\begin{array}{l}\text { Employees } \\
N=39 \\
(57 \% \text { female* } \\
\text { (1) } n=19 \\
\text { (2) } n=20 \\
M=47.5 \pm 8.29^{\star}\end{array}$ & $\begin{array}{l}28 \text { weeks } \\
\text { (1) PA+SMS: PA program two } \\
\text { 1-hours sessions per week, text } \\
\text { messaging cues before the night } \\
\text { before PA sessions and } 1 \text {-hour } \\
\text { before PA sessions (4/week) } \\
\text { (2) PA program only }\end{array}$ & $\begin{array}{l}\text { Habit: SRBAl } \\
\text { PA: IPAQ }\end{array}$ & $\begin{array}{l}\text { Mixed model: } \\
\text { - habit increases over time in both groups, } \\
\text { but higher in (1) }(B=0.05, p<0.01) \text { than } \\
\text { in }(2)(B=0.02, p=0.02) \\
\text { General linear model: PA at follow-up } \\
\left.\text { higher in (1) } t_{(14)}=2.20, p=0.04\right) \text { than in } \\
\left.\text { (2) } t_{(7)}=1.28, p=0.24\right)\end{array}$ \\
\hline
\end{tabular}

Bird et al. (2018) TPB, eTPB

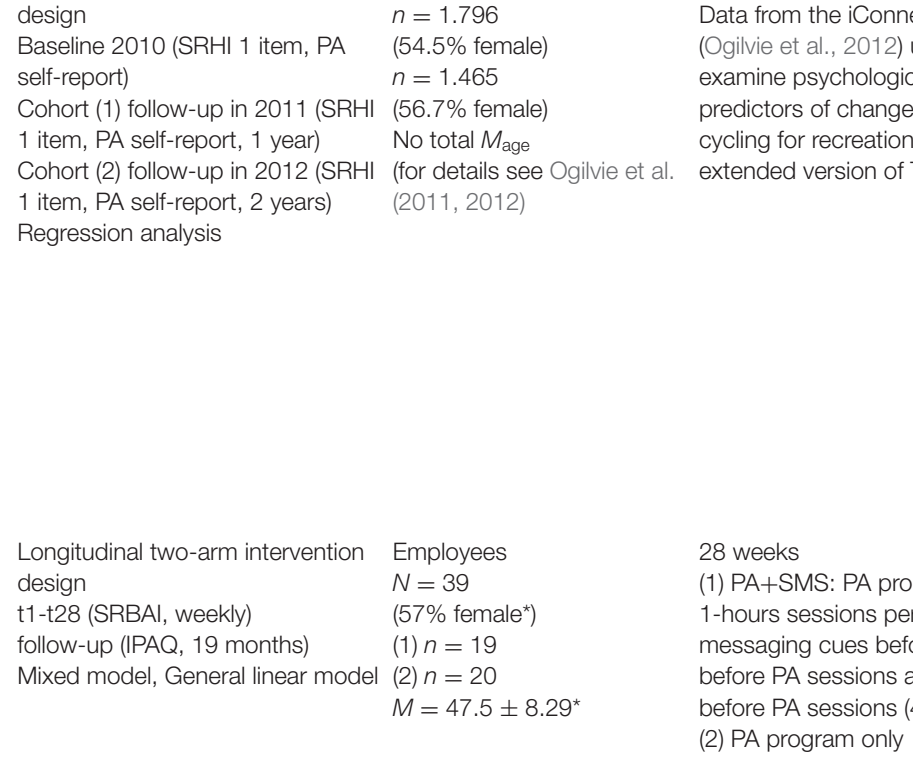


TABLE 2 | Continued

\begin{tabular}{|c|c|c|c|c|c|c|}
\hline $\begin{array}{l}\text { References } \\
\text { Country of } \\
\text { origin }\end{array}$ & Theory/model & $\begin{array}{l}\text { Study design (measurement } \\
\text { occasions, statistics) }\end{array}$ & $\begin{array}{l}\text { Sample (final sample } \\
\text { size, gender proportion, } \\
\text { mean age) }\end{array}$ & $\begin{array}{l}\text { Treatment (content, length, } \\
\text { duration, frequency) }\end{array}$ & $\begin{array}{l}\text { Outcome (measurements } \\
\text { of habit and PA) }\end{array}$ & Results \\
\hline $\begin{array}{l}\text { Fournier et al. } \\
\text { (2018) } \\
\text { France }\end{array}$ & - & $\begin{array}{l}\text { Longitudinal two-arm intervention } \\
\text { design } \\
\text { Baseline (SRBAl, IPAQ) } \\
\text { t1 (SRBAl, IPAQ, } 5 \text { months) } \\
\text { t2 (IPAQ, } 7 \text { months) } \\
\text { t3 (IPAQ, } 9 \text { months) } \\
\text { t4 (SRBAl, IPAQ, } 12 \text { months) } \\
\text { Mixed model, General linear model }\end{array}$ & $\begin{array}{l}\text { Cardio-vascular patients } \\
N=45 \\
\text { (1) } n=22 \text { (4.5\% female) } \\
M=62.5 \pm 10.7 \\
\text { (2) } n=23 \text { (8.7\% female) } \\
M=63.5 \pm 8.1\end{array}$ & $\begin{array}{l}5 \text { months } \\
\text { (1) progressively autonomous PA } \\
\text { group: } 2.5 \text { months } 2 \text { supervised } \\
\text { sessions and } 1 \text { autonomous } \\
\text { session per week, } 2.5 \text { months } 1 \\
\text { supervised session and } 2 \\
\text { autonomous sessions per week, } \\
\text { autonomy-supportive coaching } \\
\text { style, individualized exercise } \\
\text { prescriptions, pamphlet on PA, } \\
\text { calendar (Gardner et al., 2012), } \\
15 \text { min phone interview every } 2 \\
\text { weeks, SMS cues every day } \\
\text { before PA session } \\
\text { (2) supervised PA group: } 2 \\
\text { supervised sessions and } 1 \\
\text { autonomous session per week }\end{array}$ & $\begin{array}{l}\text { Habit: SRBAI } \\
\text { PA: IPAQ }\end{array}$ & $\begin{array}{l}\text { Mixed model: } \\
\text { Differences between groups in PA after the } \\
\text { program n.s. } \\
\text { General linear model: } \\
\text { - Habit increases over time in both groups } \\
\left(\eta^{2}=0.24, p=0.012\right) \\
\text { - Differences between groups in habit n.s. }\end{array}$ \\
\hline $\begin{array}{l}\text { Kaushal et al. } \\
\text { (2017a) }\end{array}$ & $\begin{array}{l}\text { Dual-process } \\
\text { approach (Evans, } \\
\text { 2008), Habit model } \\
\text { (Lally and Gardner, } \\
\text { 2013) }\end{array}$ & $\begin{array}{l}\text { Longitudinal observational design } \\
\text { Baseline (2x SRBAI, GLTEQ) } \\
\text { follow-up (2x SRBAl, GLTEQ, } 6 \\
\text { weeks) } \\
\text { Bivariate correlation, Structural } \\
\text { equation models }\end{array}$ & $\begin{array}{l}\text { Gym members } \\
N=181(64 \% \text { female }) \\
M=43.3 \pm 15.3\end{array}$ & No treatment & $\begin{array}{l}\text { Habit: } 2 \times \text { SRBAI (specified } \\
\text { for preparation and } \\
\text { performance habit) } \\
\text { PA: GLTEQ }\end{array}$ & $\begin{array}{l}\text { Bivariate correlation between exercise at } \\
\text { week } 6 \text { and preparatory habit }(r=0.22 \text {, } \\
p<0.01 \text { ) and performance habit }(r=0.20, p \\
=0.01) \\
\text { Structural equation models: } \\
\text { - Habit preparation ( } B=0.20, p=0.03 \text { ) sig. } \\
\text { predicts behavior at week } 6 \\
\text { - Habit preparation ( } B=0.18, p=0.04) \\
\text { predicts change in behavior from baseline } \\
\text { to week } 6\end{array}$ \\
\hline $\begin{array}{l}\text { Kaushal et al. } \\
\text { (2018) } \\
\text { Canada }\end{array}$ & M-PAC & $\begin{array}{l}\text { RCT } \\
\text { Baseline (2x SRBAI, GLTEQ, } \\
\text { accelerometer), post-test ( } 2 x \\
\text { SRBAI, GLTEQ, accelerometer, } 8 \\
\text { weeks) } \\
\text { Bivariate correlation, } \\
\text { Mediation analysis }\end{array}$ & $\begin{array}{l}\text { New gym members } \\
N=94 \\
\text { (1) } n=41 \text { (83\% female) } \\
M=38.21 \pm 13.98 \\
\text { (2) } n=53 \text { (81\% female) } \\
M=40.30 \pm 14.69\end{array}$ & $\begin{array}{l}8 \text { weeks } \\
\text { (1) intervention: workshop, } \\
\text { consistent exercise plan, develop } \\
\text { a preparatory exercise habit, } \\
\text { implement cue rituals, booster } \\
\text { telephone call (week 4) (for } \\
\text { details see Kaushal et al., 2017b) } \\
\text { (2) control: no treatment }\end{array}$ & $\begin{array}{l}\text { Habit: } 2 \times \text { SRBAl (specified } \\
\text { for preparation and } \\
\text { performance habit) } \\
\text { MVPA: } \\
\text { GLTEQ, accelerometer } \\
\end{array}$ & $\begin{array}{l}\text { Bivariate correlations between } \\
\text { - Habit preparation and self-reported MVPA } \\
(r=0.25, p<0.01) \\
\text { - Habit performance and self-reported } \\
\text { MVPA }(r=0.23, p<0.05) \text { and } \\
\text { accelerometry }(r=0.20, p<0.05) \\
\text { Mediation } \\
\text { - Preparatysis: } \\
\text { predicts behavior change in self-reported } \\
\text { PA } \\
\text { - Indirect effect from group to self-reported } \\
\text { PA via preparatory habit }[B=0.10, \mathrm{Cl} \\
\text { (0.01, 0.33)] }\end{array}$ \\
\hline
\end{tabular}

$N=45$

$n=22(4.5 \%$ female $)$ $\pm 10.7$ $=23(8.7 \%$ female $)$

2 (IPAQ, 7 month

t4 (SRBAl, IPAQ, 12 months)

supervised session and
autonomous sessions $p$

stonomy-supportive coaching

pamphlet on PA,

for preparation an

ormance habit)

predicts behavior at week 6

Habit preparation $(B=0.18, p=0.04)$

predicts change in behavior from baseline

Bivariate

etween

consistent exercise plan, develop performance habit)

(2) $n=53(81 \%$ fema

Bivariate correlation, $\quad M=40.30 \pm 14.69$

telephone call (week 4) (for

details see Kaushal et al., 2017 
TABLE 2 | Continued

\begin{tabular}{l}
$\begin{array}{l}\text { References } \\
\text { Country of } \\
\text { origin }\end{array}$ \\
\hline
\end{tabular}

\section{Sample (final sample Treatment (content, length, Outcome (measurements Results \\ of habit and PA)}

size, gender proportion, duration, frequency)

Mullan et al.

(2016)

Longitudinal observational design Pregnant women

No treatment

$\begin{array}{ll}\text { Baseline (SRHI) } & N=117 \\ \text { t1 (PA 2 items, } 1 \text { week) } & M=30.17 \pm 4.46\end{array}$

No treatment

Bivariate correlation, Hierarchical

regression analysis

Pfeffer and Strength model of

Strobach (2018) self-contro

Germany
Phillips and

Gardner (2016)

USA
Longitudinal observational design Baseline (SRBAI, PA 1 item) t1 (PA 1 item, 1 week)

Bivariate correlation,Multiple regression analysis
Longitudinal observational design University students and staff No treatment Baseline (2x SRBAI, PA 1 item)

t1 (2x SRBAI, PA 1 item, electronic Students (65\% female)

daily diary reports, 1 month) $N=118$

University students

$N=124(52.4 \%$ female $)$

No treatment $M=23.59 \pm 2.76$

regression analysis, ANOVA

$M=19.48 \pm 2.08$

Staff/faculty (89\% female)

$M=37.61 \pm 13.82$

\section{Habit: SRH}

PA: 2 items

"In the previous week, to

what extent did you perform physical activity following the recommended

guidelines?"

"In the previous week, how often did you perform physical activity following the

recommended guidelines?

Habit: SRBAl

Bivariate correlation between:

PA: 1 item (number of hours - Habit and PA at baseline PA $(r=0.41, p<$ of vigorous PA during last 7 days)

Habit and PA at $\mathrm{t} 1(r=0.29, p<0.01)$ Regression analysis:

- Habit (as moderator) predicts PA ( $B=0.23$, $p<0.01$ ) (model with age, sex, self-control) - Interaction effect between self-control and habit (as moderator) predicts PA $(B=0.19$, $p=0.028$ ) (model with age, sex, selfcontrol, habit)

- Habit (as mediator) predicts PA at t1 ( $\beta=$ $0.28, p=0.01$ ) (model with age, sex, self-control)

Habit: 2x SRBAI (specified Bivariate correlation between instigation and for preparation and perfor

PA: 1 item "How often do you exercise?", electronic daily diary reports exection habit and both PA out baseline and $t$ ( $r$ values between $r=0.22$ and $r=0.56$ with $p<0.05$ and $p<0.01$ ) Multiple regression analysis:

only instigation habit predicts PA at t2 (daily diary report: $\beta=0.31, t_{(3,108)}=2.56, p=$ 0.01 ; PA 1 item: $\beta=0.39, t_{(3,107)}=3.16, p<$ $0.01)$

ANOVA:

- Change in PA (from high at baseline to low at t1) associated with change in instigation habit (slope $=-0.46, p<0.05$ )

- Change in PA (from low at baseline to high at t1) not associated with change in

instigation habit (slope $=0.21, p=0.22$ ) 
TABLE 2 | Continued

\begin{tabular}{|c|c|c|c|c|c|c|}
\hline $\begin{array}{l}\text { References } \\
\text { Country of } \\
\text { origin }\end{array}$ & Theory/model & $\begin{array}{l}\text { Study design (measurement } \\
\text { occasions, statistics) }\end{array}$ & $\begin{array}{l}\text { Sample (final sample } \\
\text { size, gender proportion, } \\
\text { mean age) }\end{array}$ & $\begin{array}{l}\text { Treatment (content, length, } \\
\text { duration, frequency) }\end{array}$ & $\begin{array}{l}\text { Outcome (measurements } \\
\text { of habit and PA) }\end{array}$ & Results \\
\hline $\begin{array}{l}\text { Rhodes et al. } \\
\text { (2019b) } \\
\text { Canada }\end{array}$ & TPB, M-PAC & $\begin{array}{l}\text { Longitudinal two-arm intervention } \\
\text { design } \\
\text { Baseline (SRBAl, accelerometry) } \\
\text { t1-t3 (accelerometry, mGLTEQ, } \\
\text { weekly) } \\
\text { t1 (SRBAl, } 6 \text { weeks) } \\
\text { t2 (SRBAl, } 13 \text { weeks) } \\
\text { t3 (SRBAl, } 26 \text { weeks) } \\
\text { Bivariate correlation, Logistic } \\
\text { regression analysis }\end{array}$ & $\begin{array}{l}\text { Parents } \\
N=102 \\
\text { (1) } n=50 \text { (83\% female) } \\
M=42.96 \pm 5.71 \\
\text { (2) } n=52 \text { (75,5\% female) } \\
M=42.17 \pm 5.68\end{array}$ & $\begin{array}{l}26 \text { weeks } \\
\text { (1) education group: receiving } \\
\text { information about the benefits of } \\
\text { MVPA } \\
\text { (2) education + planning group: } \\
\text { receiving additional information } \\
\text { on planning for PA for their child } \\
\text { (for details see Rhodes et al., } \\
2019 \text { a) }\end{array}$ & $\begin{array}{l}\text { Habit: SRBAl } \\
\text { PA: accelerometry, mGLTEQ }\end{array}$ & $\begin{array}{l}\text { Bivariate correlation between habit and } \\
\text { - PA via accelerometry at baseline }(r=0.20 \text {, } \\
p<0.05) \text { and at } \mathrm{t} 1(r=0.33, p<0.05) \text {, at } \\
\text { t2 } \mathrm{n} . \mathrm{s} \text {. } \\
\text { - PA via mGLTEQ across the trail } \\
\text { ( } r=0.36-0.51, p<0.05) \\
\text { Regression analysis: } \\
\text { - Habit predicts PA accelerometry from } \mathrm{t} 1 \text { to } \\
\text { t2 of successful compared to unsuccessful } \\
\text { intenders [OR = 1.99, } p<0.01 ; 95 \% \mathrm{Cl} \\
\text { (1.31, 3.04)] } \\
\text { - Habit predicts mGLTEQ at all time periods } \\
\text { [baseline to t1: } \mathrm{OR}=1.60, p<0.05 ; 95 \% \\
\mathrm{Cl}(1.18,2.17) ; \mathrm{t} 1 \text { to } \mathrm{t} 2: \mathrm{OR}=2.08, p< \\
0.01 ; 95 \% \mathrm{Cl}(1.33,3.26) ; \mathrm{t} 2 \text { to } \mathrm{t} 3: \mathrm{OR}= \\
1.88, p<0.01 ; 95 \% \mathrm{Cl}(1.20,2.93)]\end{array}$ \\
\hline $\begin{array}{l}\text { Schwarzer et al. } \\
\text { (2017) } \\
\text { Italy, Spain, } \\
\text { Greece }\end{array}$ & HAPA & $\begin{array}{l}\text { RCT } \\
\text { Baseline (SRBAl, GPPAQ) } \\
\text { t1 (SRBAI, GPPAQ, } 3 \text { months) } \\
\text { t2 (SRBAl, GPPAQ, } 6 \text { months) } \\
\text { Bivariate correlation, Structural } \\
\text { equation model }\end{array}$ & $\begin{array}{l}\text { Adults } \\
\begin{array}{l}N=638 \\
\text { (1) } n=315 \text { (61.9\% female) } \\
\text { (2) } n=323 \text { (57.6\% female) } \\
M=43.01 \pm 10.82\end{array}\end{array}$ & $\begin{array}{l}6 \text { months } \\
\text { (1) Intervention: dynamic digital } \\
\text { platform (personalized paths to } \\
\text { self-set goals, personalized } \\
\text { feedback and rewards, weekly } \\
\text { schedule according goals, } \\
\text { strategies to overcome barriers) } \\
\text { (2) Control: static digital platform } \\
\text { (non-personalized information } \\
\text { and feedback, recommendations } \\
\text { according to baseline profile) }\end{array}$ & $\begin{array}{l}\text { Habit: SRBAl } \\
\text { PA: GPPAQ }\end{array}$ & $\begin{array}{l}\text { Bivariate correlations between habit at } \mathrm{t} 2 \text { and } \\
\text { - PA at baseline }(r=0.18, p<0.01) \\
\text { - PA at } \mathrm{t} 1(r=0.16, p<0.01) \\
\text { - PA at } \mathrm{t} 2(r=0.16, p<0.01) \\
\text { Structural equation model: } \\
\text { PA at t } 2 \text { was predicted by habit at t2 (men: } \\
\beta=0.17 \text {, women: } \beta=0.23) \text { (model with } \\
\text { motivation, planning at } \mathrm{t} 1 \text { and } \\
\text { self-monitoring at } \mathrm{t} 1 \text { ) }\end{array}$ \\
\hline
\end{tabular}




\begin{tabular}{|c|c|c|c|c|c|c|}
\hline $\begin{array}{l}\text { References } \\
\text { Country of } \\
\text { origin }\end{array}$ & Theory/model & $\begin{array}{l}\text { Study design (measurement } \\
\text { occasions, statistics) }\end{array}$ & $\begin{array}{l}\text { Sample (final sample } \\
\text { size, gender proportion, } \\
\text { mean age) }\end{array}$ & $\begin{array}{l}\text { Treatment (content, length, } \\
\text { duration, frequency) }\end{array}$ & $\begin{array}{l}\text { Outcome (measurements } \\
\text { of habit and PA) }\end{array}$ & Results \\
\hline $\begin{array}{l}\text { van Bree et al. } \\
\text { (2016) } \\
\text { Netherlands }\end{array}$ & HAPA & $\begin{array}{l}\text { Longitudinal observational design } \\
\text { Baseline (intention, SRBAl, habit } \\
\text { items, PA } 1 \text { item) } \\
\text { t1 (action planning, } 3 \text { months) } \\
\text { t2 (PA } 1 \text { item, } 6 \text { months) } \\
\text { t3 (SRBAl, habit items, } 12 \text { months) } \\
\text { Bivariate correlation, } \\
\text { Regression analysis }\end{array}$ & $\begin{array}{l}\text { Older adults } \\
\text { Study 1: } \\
N=469 \text { (53\% female) } \\
M=63.07 \pm 7.61 \text { (data } \\
\text { from an RCT-control group, } \\
\text { for details see van Stralen } \\
\text { et al., 2011) } \\
\text { Study 2: } \\
N=322 \text { (49\% female) } \\
M=64.31 \pm 9.39 \text { (data } \\
\text { from an RCT-control group, } \\
\text { for details see Peels et al., } \\
\text { 2013) }\end{array}$ & No treatment & $\begin{array}{l}\text { Study 1: } \\
\text { Habit: SRBAI } \\
\text { PA: } 1 \text { item from SQUASH } \\
\text { "On how many days per } \\
\text { week are you, in total, at } \\
\text { least moderately physically } \\
\text { active for at least } 30 \text { min by } \\
\text { undertaking, for example, } \\
\text { heavy walking, cycling, } \\
\text { chores, gardening, sports or } \\
\text { other moderate or vigorous } \\
\text { physical activities?" } \\
\text { Study } 2 \text { : } \\
\text { Habit: } 2 \text { items from SRBAl } \\
\text { and } 2 \text { items from SRHI: } \\
\text { "Being sufficiently physically } \\
\text { active is something ... I do } \\
\text { automatically, ... I start } \\
\text { doing before I realize l'm } \\
\text { doing it, ... I would find hard } \\
\text { not to do, ... I have no need } \\
\text { to think about doing." } \\
\text { PA: like in study } 1\end{array}$ & $\begin{array}{l}\text { Study 1: } \\
\text { Bivariate correlation between } \\
\text { - Habit (baseline) and PA (t2) }(r=0.18 \text {, } \\
p<0.01) \\
\text { - PA (t2) and habit (t3) ( } r=0.29, p<0.01) \\
\text { Regression analysis: } \\
\text { - PA (t2) predicts habit (t3) (âb } b_{c s}=0.18 \text {, } \\
p<0.01 \text { ) (model with intention at baseline } \\
\text { and action planning at t1) } \\
\text { Study 2: } \\
\text { Bivariate correlation between } \\
\text { - Habit (baseline) and PA (t2) }(r=0.37 \text {, } \\
p<0.01) \\
\text { - PA (t2) and habit (t3) ( } r=0.42, p<0.01 \text { ) } \\
\text { Regression analysis: } \\
\text { - PA (t2) predicts habit (t3) (âb } c=0.21 \text {, } \\
p<0.01 \text { ) (model with intention at baseline } \\
\text { and action planning at } \mathrm{t} 1) \\
\end{array}$ \\
\hline $\begin{array}{l}\text { van Bree et al. } \\
\text { (2017) } \\
\text { Netherlands }\end{array}$ & $\begin{array}{l}\text { Habit formation } \\
\text { theory (Lally et al., } \\
\text { 2008) }\end{array}$ & $\begin{array}{l}\text { Longitudinal observational design } \\
\text { Baseline (SRBAl, habit items, PA } 1 \\
\text { item) } \\
\text { t1 (SRBAl, habit items, PA } 1 \text { item, } \\
6 \text { months), } \\
\text { t2 (SRBAl, habit items, PA } 1 \text { item, } \\
12 \text { months) } \\
\text { Bivariate correlation, Structural } \\
\text { equation models (cross-lagged } \\
\text { panel design) }\end{array}$ & $\begin{array}{l}\text { Older adults } \\
\text { Study 1: } \\
N=1.976^{\star} \text { ( } 57 \% \text { female) } \\
M=63.36 \pm 8.66 \text { (for } \\
\text { details see van Stralen et al., } \\
\text { 2011) } \\
\text { Study 2: } \\
N=2.140^{\star} \\
M=62.75 \pm 8.57 \text { (for } \\
\text { details see Peels et al., } \\
\text { 2013) }\end{array}$ & No treatment & $\begin{array}{l}\text { Study 1: } \\
\text { Habit: SRBAI } \\
\text { PA: } 1 \text { item from SQUASH } \\
\text { "On how many days per } \\
\text { week are you, in total, at } \\
\text { least moderately physically } \\
\text { active for at least } 30 \text { min by } \\
\text { undertaking, for example, } \\
\text { heavy walking, cycling, } \\
\text { chores, gardening, sports or } \\
\text { other moderate or vigorous } \\
\text { physical activities?" } \\
\text { Study 2: } \\
\text { Habit: } 2 \text { items from SRBAl } \\
\text { and } 2 \text { items from SRHI: } \\
\text { "Being sufficiently physically } \\
\text { active is something ... I do } \\
\text { automatically, ... I start } \\
\text { doing before I realize I'm } \\
\text { doing it, ... I would find hard } \\
\text { not to do, ... I have no need } \\
\text { to think about doing." } \\
\text { PA: like in study } 1\end{array}$ & $\begin{array}{l}\text { Bivariate correlation between habit (baseline, } \\
\mathrm{t} 1, \mathrm{t} 2) \text { and PA (baseline, } \mathrm{t} 1, \mathrm{t} 2) \text { in } \\
\text { - Study } 1(r=0.26-0.34, p<0.01) \\
\text { - Study } 2(r=0.38-0.51, p<0.01) \\
\text { Structural equation models: } \\
\text { Study 1: } \\
\text { - Mediation effect for habit(baseline) -PA(t1)- } \\
\text { habit(t2) path [product of coefficients' } z= \\
2.73, p<0.01, \mathrm{Cl}(0.004 ; 0.019), \text { âb } \\
\text { cs }= \\
0.011 P M E=2.7 \%] \\
\text { - Marginal sig. for PA(baseline)-habit(t1)- } \\
\text { PA(t2) path }[z=1.84, p=0.067, \mathrm{Cl}(0.000 \text {; } \\
\text { 0.011), âbcs }=0.01, P M E=2.4 \%] \\
\text { Study 2: } \\
\text { - Mediation effect for the path PA(t0)- } \\
\text { habit(t1)-PA(t2) }[z=4.07, p<0.01, \mathrm{Cl} \\
\left.\text { (0.016; } 0.044), a \hat{b} b_{c s}=0.03, P M E=10.8 \%\right] \\
\text { - Mediation effect of the } \\
\text { habit(to)PA(t1)-habit(t2) path n.s. } \\
\end{array}$ \\
\hline
\end{tabular}




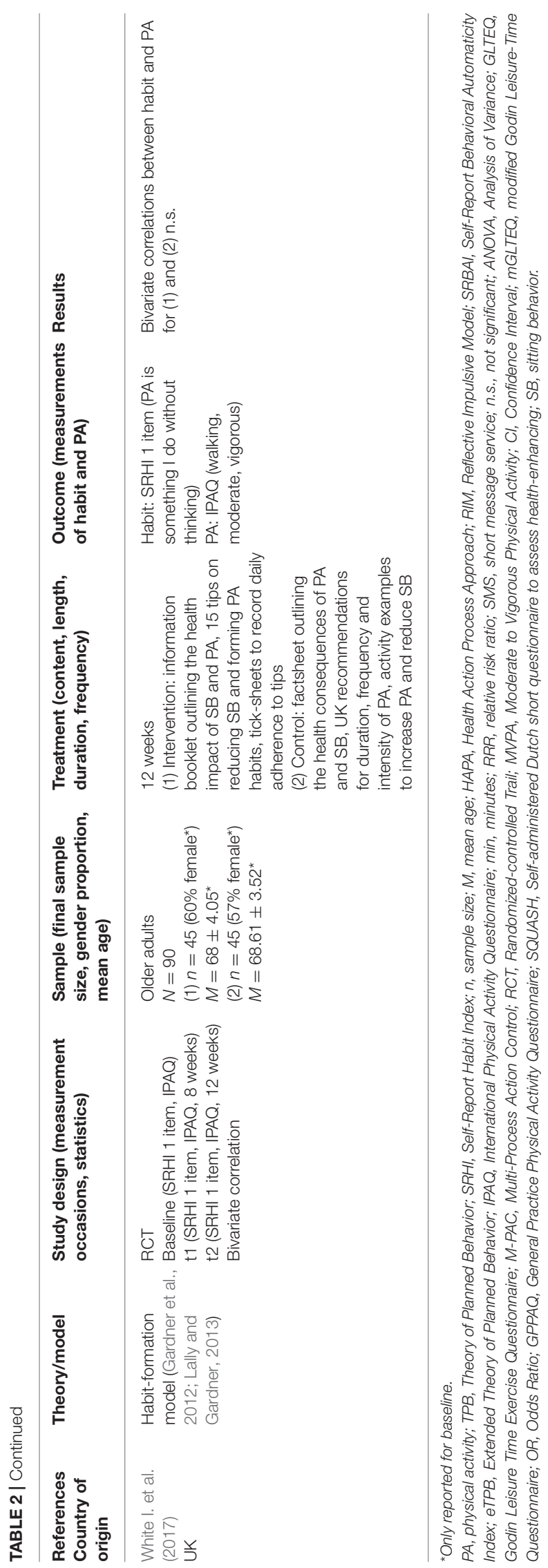

conscious processes (Kaushal et al., 2018; Rhodes et al., 2019b). The framework involves different phases of behavior, from initiation to continuation, and recommends appropriate targets, such as triggering cues (Rhodes, 2017). Another approach was recently introduced by Strobach et al. (2020). This heuristic Physical Activity Adoption and Maintenance (PAAM) model includes both implicit and explicit processes as the basis for physical activity maintenance (Strobach et al., 2020).

Beyond that, a consistent habit theory should be considered. There are various definitions of habit existing from different authors. Instead of revising existing theories of habit, scientists should take into account a common consensus about central elements characterizing habit. Although Lally and Gardner (2013) already developed a framework for habit formation, only two studies of this review used this as theoretical background to develop new habits (Kaushal et al., 2017a; White I. et al., 2017). In their paper, Lally and Gardner (2013) broke the habit formation process down into detailed stages which can be applied in interventions to develop a physical activity-related habit. Future research could be more efficient with a unitary understanding of the habit construct and, thus, tap the full potential of habit and its effects on physical activity behavior.

\section{Contribution to Habit Research}

The positive correlations between habit and physical activity indicates that habit plays an important role in physical activity promotion. However, the question remains whether habit influences physical activity or vice versa. Only a few studies analyzed the direct effect of habit on physical activity, but this helps to solely quantify the relationship. Most included studies used complex models with other psychological variables and could only present indirect effects of habit. Due to the heterogeneity of study designs, conclusions about the effect of habit on physical activity must be treated with caution. However, included studies can contribute to topics currently discussed in habit research.

Intention was a central variable in various studies and different approaches were used to relate the constructs of intention and habit to explain behavior. This reflects the relevance of the current discussion about the complex interplay between intention, habit, and behavior, which needs to be clarified. In a recently published review, Gardner et al. (2020b) addressed the habit-intention interaction hypothesis of Triandis (1977) and examined 52 studies focusing on the predictive effect of the habit-intention relationship on behavior. Physical activity studies showed mixed support of the hypothesis that habit impulses will preside over intentions in stable settings. In conclusion, the authors argued that habits have the potential to dominate over intentions and intentions have the potential to dominate over habits, but this interaction depends on the level of self-control. Our review does not support the assumption of previous research that intention becomes less predictive of physical activity as habit strength increases. In several studies, no direct relationship between intention and habit was found, which significantly contributed to explain physical activity (Allom et al., 2016; Mullan et al., 2016; van Bree et al., 2016; Kaushal et al., 2017a). Authors concluded that intention and habit should be viewed 
as individual variables influencing physical activity behavior on different paths. Conscious and non-conscious processes both independently contribute to behavior change, which supports the idea of a dual-process approach (Allom et al., 2016; Mullan et al., 2016; Kaushal et al., 2017a). Therefore, we consider intention as a key variable for physical activity behavior, besides individual habit strength. We agree with Kaushal et al. (2017a) that both variables are highly relevant in physical activity behavior change processes and should not compete against each other.

Some authors focused on self-regulatory processes such as self-control (Pfeffer and Strobach, 2018), which was operationalized through planning and self-monitoring in intervention studies (Schwarzer et al., 2017; White I. et al., 2017; Fournier et al., 2018; Kaushal et al., 2018; Rhodes et al., 2019b). Self-regulatory strategies might have an essential role in the habit formation process. Also, Lally and Gardner (2013) incorporated these strategies in their framework and recommended both planning and self-monitoring for action initiation and behavior repetition, resulting in successful habit formation. Only a few studies applied self-regulatory constructs and presented inconclusive results on the effect of planning and self-monitoring on habit formation (Schwarzer et al., 2017; White I. et al., 2017; Fournier et al., 2018; Kaushal et al., 2018; Rhodes et al., 2019b). Nevertheless, authors proposed planning and self-monitoring as relevant variables, which could support the development of habits as Lally and Gardner (2013) already stated. Especially planning is conducive to the habit formation process by acting as a cue-related factor and "thus provides the cognitive architecture through which intentional actions may become habitual" (Gardner and Lally, 2018, p. 213).

When discussing the effect of physical activity on habit, Gardner (2015) distinguished between habit formation studies and studies measuring ongoing habits, because only formation studies have the potential to create new habits. Two studies aimed to build habits and successfully used physical activity as intervention content to form habit (Fournier et al., 2016, 2018). These results show that a physical activity program itself can effectively contribute to develop habits. This concurs with the framework by Gardner and Lally (2018), in which behavior repetition is an important step of the habit formation process. One observational study found an indirect effect, in which most likely an ongoing habit was predicted via physical activity frequency (van Bree et al., 2016). However, the causality of a behavior-habit effect remains unclear. The prediction of an ongoing habit through physical activity could result in false conclusions, because the existing habit positively influenced physical activity beforehand. Therefore, this explains the prediction of physical activity through habit rather than the prediction of habit through physical activity.

Phillips and Gardner (2016) were the first authors to distinguish between instigation and execution habit. To our knowledge this is the only experimental study investigating the role of these constructs in physical activity behavior so far. In this study instigation habit was a significant predictor of physical activity. The authors assumed that the habitual instigation of physical activity might be more valuable for a regular performance of behavior than the habitual execution of the behavior itself. Execution habit was not found as a predictor in their study. However, Gardner et al. (2020a) hypothesized that the habitual execution of physical activity may influence other constructs such as self-efficacy or affective judgments resulting in a higher physical activity engagement. The potential of execution habit has not been evaluated in experimental studies yet. The hypothesis of Gardner et al. (2020a) should be examined in future research to investigate the role of execution habit during physical activity sessions. Furthermore, we assume that the quality and volume of training could be ensured through the habituation of certain exercise sequences. Especially in intervention studies the content and performance of physical activity could be warranted through execution habits. It may be more successful to focus not only on the initiation of physical activity but also on the output of physical activity sessions to fulfill the international physical activity recommendations.

Different to the approach of Phillips and Gardner (2016), the distinction between preparatory and performance phase could be a practical concept in habit research. In the studies of Kaushal et al. (2017a, 2018), the assessment of habit refers to the behavioral phases before and during the exercise behavior. The preparatory phase of exercising consists of several sequences of preparatory actions like packing the gym bag or going to the gym. In the view of Phillips and Gardner (2016), these actions belong to the execution of the whole exercise behavior. However, they do not distinguish in the assessment of habit between habitually doing before and during the exercises. The assessment of execution habit by Phillips and Gardner (2016) focused only on cue-behavior associations while exercising ("Once I am exercising... [... is something I do automatically]"). Therefore, habitual preparatory actions were only assessed in the studies of Kaushal et al. (2017a, 2018) and findings revealed preparatory habit as the significant predictor for exercising. Altogether, the approaches of Phillips and Gardner (2016) and Kaushal et al. (2017a, 2018) both have the eligibility to contribute to habit research, but it may be that the combination of these concepts encapsulates the habit-behavior relationship in its entirety. Consequently, the assessment of habitually deciding and habitually doing, which could be divided into a preparatory and performance phase, would result in three SRHI-stems: "Deciding to exercise... [... is something I do automatically]," "When I prepare to exercise... [... is something I do automatically]," "Once I am exercising... [... is something I do automatically]." Future studies could examine and compare the predictive power of these SRHI-stems to gather more information about the relevance of the approaches of Phillips and Gardner (2016) and Kaushal et al. $(2017 \mathrm{a}, 2018)$ in the up-take or maintenance of physical activity.

\section{Conceptual Considerations}

This review focused on studies applying the SRHI or SRBAI to assess habit. Previously published literature showed that these instruments are the most commonly used habit measures (Lally and Gardner, 2013; Gardner, 2015; Rebar et al., 2016). Based on homogeneity, changes in habit strength are comparable 
between studies (Rebar et al., 2016). However, data relies on selfreport, resulting in questionable construct validity, because nonconscious regulatory processes may not be precisely expressed (Gardner and Tang, 2014; Rebar et al., 2016). Using selfreported measurements to assess unconscious processes might be a general problem in examining implicit constructs. Because of its automatic character, habit is performed without deliberating behavioral choices.

A reliable measure of habit should incorporate all components of habit, especially contextual cue dependency as a central characteristic of habit, which is neglected in the SRHI and its variations such as the SRBAI (Gardner, 2015). The original survey should be adapted, involving the contextual cue related to the behavior ("Behavior $\mathrm{X}$ in Context $\mathrm{Y}$ is something I do automatically.") (Gardner, 2015, p. 283; Hagger, 2019). Rebar et al. (2016) recommended alternative methods not relying on self-reported measures to ensure validity of the habit assessment. Theoretically, implicit methods would be the most valid measures, but the practicability in experimental field studies is insufficient (Gardner, 2015). Therefore, self-reported measures are still the dominating assessment tool in applied research. One option to measure habit in daily life is to apply Ecological Momentary Assessment (EMA) methods, which could show that habitual responses depend on environmental contexts. Digital technologies such as smartphones and tablets can record large amounts of data and this enables a detailed analysis of habits in everyday life (Carden and Wood, 2018). EMA methods offer the opportunity to measure behavior in real-time and allow researchers to assess various factors simultaneously. Psychological components can be assessed directly before, during, or after physical activity, reflecting reality more accurately. Moreover, objective and subjective measurements, such as accelerometer and selfreported questionnaires, can be combined in experimental studies. Additionally, the application of wearable technology could facilitate the efficient implementation of complex study designs (Ebner-Priemer et al., 2019).

The application of EMA methods would contribute to the demand of Lally and Gardner (2013) for multiple measurements over long time periods to assess habit. Several measurement occasions would make the habit formation process related to physical activity behavior more comprehensible and could show changes in habit and physical activity behavior. To realize effects over time and relate habit to physical activity, the assessment of both constructs at all measurement occasions is required. Although the amount of measurement occasions varied highly in the included studies, several authors presented promising approaches to fulfill these recommendations (Schwarzer et al., 2017; van Bree et al., 2017; White I. et al., 2017; Fournier et al., 2018; Rhodes et al., 2019b). So far, longitudinal studies are rare, because high-quality studies over a long time period are costly and time consuming. The included study by Rhodes et al. (2019b) could serve as an example for the application of state-of-the-art technology to assess physical activity behavior and for the implementation of multiple measurement occasions for habit. Physical activity behavior was tracked with an accelerometer in everyday life for 6 months and, in addition, habit data were collected via self-report on four occasions within this period. This study design met central recommendations published by Gardner and Lally (2018). Three other studies measured habit and physical activity only once at different measurement occasions and related the two constructs (Allom et al., 2016; Arnautovska et al., 2016; Mullan et al., 2016). Even though this study design has been considered as longitudinal, the development of both habit and physical activity cannot be analyzed. Therefore, this study design is not advisable for measuring long-term effects. In future research, study designs with many measurement occasions are required.

When discussing the study design, also study analysis methods should be reconsidered. The construct of habit depends on cue, behavior, and person-related factors. Hence, sum scores for habit across all participants are insufficient because the habit-behavior relationship develops individually. Consequently, within-designs in multi-level analysis with multiple measurement occasions would be most valuable (Gardner and Lally, 2018). Two studies applied mixed-model analysis to capture the influence of the intervention program on the participants' habit and physical activity behavior (Fournier et al., 2016, 2018). When focusing on the direction of causality between the two constructs, cross-lagged panel designs could be beneficial (Pfeffer and Strobach, 2018). This design was adopted by van Bree et al. (2017) to model a longitudinal relationship between the constructs in three waves in two different study populations. This allowed a simultaneous analysis in both directions. Due to contrary findings in both studies, the question of causality remains unanswered. However, further studies applying this study design are needed to investigate the bidirectional association of habit and physical activity.

\section{Habit Formation and Physical Activity Maintenance}

Only a few included studies aimed to form new habits through intervention designs (Fournier et al., 2016, 2018; Schwarzer et al., 2017; White I. et al., 2017; Kaushal et al., 2018; Rhodes et al., 2019b). A central question in the literature is how long it takes to develop a certain habit. Even though these habit formation studies revealed positive effects on the habit-behavior relationship, the habit development process was transparent in only one study (Fournier et al., 2016). Fournier et al. (2016) measured the weekly strength of habit and could show the development over 28 weeks. SRBAI-scores increased over the intervention period stepwise. One plateau was reached between week 6 and 8, which is in line with previous studies. To our knowledge, only three other studies examined the time needed for habit formation. Lally et al. (2010) found that the development of a habit is asymptotic, which means there is a point from which the growth of habit strength is only marginal. A median of 66 days was calculated to reach $95 \%$ of the asymptote. Contrary to that, in the study by Fournier et al. (2016), the increase of habit strength was distributed over the complete intervention period of 28 weeks with the highest scores in the last few weeks. In another previous study, Kaushal and 
Rhodes (2015) showed that habit formation was reached after 6 weeks, with participants exercising four times each week. A total of $48 \%$ of the study population had formed a habit after 42-49 days of intervention. Walter (2017) presented similar results and detected a stagnation of SRHI scores after 8 weeks. Unfortunately, the latest intervention studies cannot contribute to the question of how long it takes to form a habit, because descriptive data in the form of means are not enough to observe that. However, intervention periods of at least 6-8 weeks are advisable, but long-term study designs should be applied to give confident recommendations for future research.

The habit formation process depends on how quickly an individual experiences a behavior as habitual (Hagger, 2019). For the identification of an action as habitual, cues in both habit and behavior must be specified (Gardner, 2015). Additionally, Hagger (2019) stated that habit formation takes not only time, but also the presence of key factors, like intention strength, perceived behavioral complexity, and the use of self-regulatory skills, is necessary. Many of the included studies involved some of these factors as variables in their models, but as discussed before, the individual development of habit was not taken into account. This procedure can be found in the study by Schwarzer et al. (2017) where motivation, planning, self-monitoring, habit strength, and physical activity were placed in a sequential manner and each variable assessed only once. Hence, the development of habit strength was not documented. Therefore, a possible influence of key factors on habit formation was not detectable. Schwarzer et al. (2017) viewed habit strength as the proximal predictor of physical activity and assumed that planning and self-monitoring become less predictive for physical activity behavior when habit strength increases. Future habit formation studies should therefore not only extend the length of intervention in combination with frequent measurement occasions, but also focus on individual differences and key factors determining habit formation. Besides, there is no threshold within the SRHI to ensure whether a habit has already been formed or not. Focusing on the influence of key factors on habit formation seems only beneficial when habit strength in participants is initially weak. Then, habit strength can develop, and one requires continuous assessment of habit over time.

Long-term studies are not only relevant for the development of habit, but also for stabilizing a new health behavior like physical activity. The overall goal is to maintain physical activity behavior after interventions as a part of the participants' daily lives. The repetition of physical activity over a longer period of time can be understood as a pattern of behavior called physical activity maintenance (Kahlert, 2015). The duration needed to reach physical activity maintenance is still unclear due to a missing consent on cut-off values (Kwasnicka et al., 2016). Kwasnicka et al. (2016) underlined in a systematic review that habit is the most continuous variable for physical activity maintenance, especially when self-regulation is low and only minimum levels of awareness and resources are available. Last measurement occasions in long-term studies included in this review were conducted between 6 months to 2 years (Bird et al., 2018) post-baseline measurement. Fournier et al. (2016) measured only physical activity after 19 months. Other authors measured both habit and physical activity at follow-up (van Bree et al., 2017; Bird et al., 2018; Fournier et al., 2018; Rhodes et al., 2019b). Contrary to long-term study designs, few observational studies narrowed their duration down to 1 week, measuring the effect of baseline habit on physical activity after 1 week (Allom et al., 2016; Arnautovska et al., 2016; Mullan et al., 2016; Pfeffer and Strobach, 2018). This does not reflect the effect of habit as a sustainable variable on physical activity maintenance. Furthermore, it is questionable whether long intervals, such as 12 months, between the measurement of habit and physical activity are effective, because it is unlikely that habit predicts physical activity 1 year later without showing a development of both variables over time (Bird et al., 2018). However, it is still unclear how long it takes to reach physical activity maintenance and therefore, long-term study designs with regular measurement occasions are deemed necessary in future habit research.

\section{Study Quality}

The applied quality assessment tool showed that study quality was equally poor, fair, and good across 15 studies. Overall, study quality of the included studies was reasonable. As mentioned before, some studies neglected the repeated measurement of both variables habit and physical activity (Allom et al., 2016; Arnautovska et al., 2016; Mullan et al., 2016), which was one reason why study quality was rated as poor. Another critical factor for poor quality was missing power analyses before the implementation of the study procedure (Allom et al., 2016; Arnautovska et al., 2016; Mullan et al., 2016; Bird et al., 2018). According to the quality assessment tools of the NHLBI (NHLBI, 2014), studies with poor quality show a significant risk of bias. Therefore, these study results must be treated with caution. A limitation of the applied assessment tools is that the overall rating relies on the reviewers' perception and not on a defined ranking.

Although two of the five studies being rated with poor quality, we would like to highlight some positive aspects. Besides other limitations, Bird et al. (2018) did not perform a power analysis, but presented a much higher sample size compared to other studies. Additionally, the study was conducted under real-world conditions which exacerbates the data collection on more time occasions, but increases the external validity of the study. Also, the study quality of Kaushal et al. (2018) was rated poorly due to methodological weaknesses. They did not address whether the participants were blinded in the RCT, and used data of participants not attending the intervention workshop for analysis in the control group. However, the detailed description of the intervention content gained our attention. Kaushal et al. (2018) applied various behavior change techniques derived from Michie et al. (2013). In terms of habit formation, they focused on repetition and substitution with the goal to form a new habit. Additionally, the M-PAC framework was tested for the first time in an RCT and this could be a promising approach for habit formation studies.

\section{LIMITATIONS}

The systematic search was carried out in only three databases, which is why a thorough snowball search was performed. The only inclusion criteria concerning study design was a longitudinal approach, and no further restrictions were added. Included 
studies focused on different research questions and this resulted in a high heterogeneity of study designs. Only studies measuring habit with the SRHI or a form of this measurement were included. As discussed before, the SRHI is widely used to capture habit, but the validity is questionable due to self-reported data. Measurement tools for physical activity were diverse, hence a comparability of physical activity content and frequency is not possible. Only a few studies analyzed the direct effect of habit on physical activity, and vice versa, and could therefore answer our hypothesis. For this reason, the findings of this review are limited.

\section{CONCLUSION AND FUTURE DIRECTIONS}

This review revealed a bidirectional relationship between habit and physical activity. Whether habit predicts physical activity or vice versa is still unclear. Based on the findings of included studies, we conclude that the direction of prediction analyses between habit and physical activity depends on the objective of research. The observation of habit influencing physical activity may be most appropriate in studies fostering physical activity maintenance, while the influence of physical activity on habit may be reasonable in experimental studies with physical activity as intervention content to form a habit. In habit research, we advise the distinction between instigation and execution habit, because both variables support the habit formation process independently.

In addition to the recommendations based on the evidence we gathered through the conduction of this systematic review, approaches of habit formation in health behaviors other than physical activity should be considered for future research as well. For example, Fritz et al. (2019) showed in a feasibility study for a weight loss intervention that African-American participants were successful in improving their nutrition and physical activity behavior through the self-selection of new habits they wanted to adopt. Typically, the health behavior for which a habit should be developed is determined by the researchers before the study begins. Especially with the aim to develop new habits, it may be an important precondition in terms of intrinsic motivation to let participants self-select appropriate habits to facilitate nutrition and physical activity behavior. This approach was also applied successfully in the physical activity domain by Lally et al. (2010). Furthermore, weight loss interventions integrated the environment of participants as a central component influencing the habit formation process (Carels et al., 2014; Fritz et al., 2019). Therefore, the modification of the environment could enhance habit strength through triggering cues which are positively related to the target behavior. Also, Bird et al. (2018) applied this approach through an infrastructure project to increase walking and cycling. On the one hand, communities and researchers can create environmental conditions to promote habit formation. On the other hand, it seems beneficial to enable participants to construct their individual environment on their own with the aim to establish healthy habits. Regarding the intervention content, weight loss interventions (Carels et al., 2014; Cleo et al., 2019) distinguish between the formation of a "good" habit and the disruption of an existing "bad" habit (Gardner and Rebar, 2019). Studies showed inconsistent results on whether the disruption of a "bad" habit solely promotes health behavior (Cleo et al., 2019) or whether a combination including the formation of a "good" habit is more promising (Carels et al., 2014). Only one study in this systematic review addressed sitting behavior as an unhealthy habit and tried to displace it with a habit for physical activity behavior (White I. et al., 2017). Although findings of this pilot study were not significant due to methodological limitations, the authors concluded that a habit-based intervention with the target to replace a "bad" with a "good" habit is promising, but that it needs further development. Future intervention studies focusing on habit formation should involve many measurement occasions (e.g., weekly) and should last at least 6-8 weeks. The framework of habit formation may be a helpful basis to conduct a promising study design including key factors for habit development, such as planning and self-monitoring. Complex studies involving variables that may influence the habit development process or disturb the maintenance of habitual behavior could be beneficial. For example, Weyland et al. (2020) investigated in a longitudinal study the influence of affect in habit formation. They showed that positive affect was significantly related to automaticity while repetition was not. Based on these results, we recommend further investigations involving determining factors of habit, such as affect. Because the process of habit formation varies between persons, the application of within-designs in future investigations is necessary. In line with Rebar et al. (2016), future studies should focus on physical activity maintenance, so that habit can function as an automatic process variable, stabilizing physical activity behavior. Long-term studies should investigate the role of habit in different stages of physical activity behavior change and maintenance. The relationship of habit and physical activity could develop over time and should therefore be observed regularly.

\section{DATA AVAILABILITY STATEMENT}

The original contributions presented in the study are included in the article/Supplementary Material, further inquiries can be directed to the corresponding author/s.

\section{AUTHOR CONTRIBUTIONS}

KF, SA, and SW generated the search term for this topic under the supervision of DJ. The screening process was allocated equally among KF, SA, and SW. KF and SA conducted the data extraction of included studies and synthesized the results of this review together. Each study was assessed for quality by KF, SA, and SW independently. The discussion was mainly conducted and written by KF and assisted by SA. SW and DJ contributed to the conceptualization of the review and revised the manuscript prior to publication. All authors contributed to the article and approved the submitted version.

\section{SUPPLEMENTARY MATERIAL}

The Supplementary Material for this article can be found online at: https://www.frontiersin.org/articles/10.3389/fpsyg. 2021.626750/full\#supplementary-material 


\section{REFERENCES}

Ajzen, I. (1991). The theory of planned behavior. Org. Behav. Hum. Decis. Process. 50, 179-211. doi: 10.1016/0749-5978(91)90020-T

Allom, V., Mullan, B., Cowie, E., and Hamilton, K. (2016). Physical activity and transitioning to college: the importance of intentions and habits. Am. J. Health Behav. 40, 280-290. doi: 10.5993/AJHB.40.2.13

Arnautovska, U., Fleig, L., O'Callaghan, F., and Hamilton, K. (2016). A longitudinal investigation of older adults' physical activity: testing an integrated dual-process model. Psychol. Health 32, 166-185. doi: $10.1080 / 08870446.2016 .1250273$

Ashe, M. C., Edwards, N. Y., Taylor, A., Burnett, L., Giangregorio, L., Milne, K., et al. (2019). Return to Everyday Activity in the Community and Home: a feasibility study for a lifestyle intervention to sit less, move more, and be strong. Pilot Feasib. Stud. 5:84. doi: 10.1186/s40814-019-0467-9

Bandura, A. (2004). Health promotion by social cognitive means. Health Educ. Behav. 31, 143-164. doi: 10.1177/1090198104263660

Bird, E. L., Panter, J., Baker, G., Jones, T., and Ogilvie, D. (2018). Predicting walking and cycling behaviour change using an extended theory of planned behaviour. J. Transport Health 10, 11-27. doi: 10.1016/j.jth.2018.05.014

Boiché, J., Marchant, G., Nicaise, V., and Bison, A. (2016). Development of the Generic Multifaceted Automaticity Scale (GMAS) and preliminary validation for physical activity. Psychol. Sport Exerc. 25, 60-67. doi: 10.1016/j.psychsport.2016.03.003

Carden, L., and Wood, W. (2018). Habit formation and change. Curr. Opin. Behav. Sci. 20, 117-122. doi: 10.1016/j.cobeha.2017.12.009

Carels, R. A., Burmeister, J. M., Koball, A. M., Oehlhof, M. W., Hinman, N., LeRoy, M., et al. (2014). A randomized trial comparing two approaches to weight loss: differences in weight loss maintenance. J. Health Psychol. 19, 296-311. doi: 10.1177/1359105312470156

Cleo, G., Glasziou, P., Beller, E., Isenring, E., and Thomas, R. (2019). Habitbased interventions for weight loss maintenance in adults with overweight and obesity: a randomized controlled trial. Int. J. Obes. 43, 374-383. doi: 10.1038/s41366-018-0067-4

Duan, Y. P., Wienert, J., Hu, C., Si, G. Y., and Lippke, S. (2017). Web-based intervention for physical activity and fruit and vegetable intake among Chinese university students: a randomized controlled trial. J. Med. Int. Res. 19:e106. doi: 10.2196/jmir.7152

Ebner-Priemer, U. W., Reichert, M., Tost, H., and Meyer-Lindenberg, A. (2019). Wearables for context-triggered assessment in psychiatry. Nervenarzt 90, 1207-1214. doi: 10.1007/s00115-019-00815-w

Ellingson, L. D., Lansing, J. E., DeShaw, K. J., Peyer, K. L., Bai, Y., Perez, M., et al. (2019). Evaluating motivational interviewing and habit formation to enhance the effect of activity trackers on healthy adults' activity levels: randomized intervention. J. Med. Int. Res. 21:e10988. doi: 10.2196/10988

Evans, J. S. (2008). Dual-processing accounts of reasoning, judgment, and social cognition. Ann. Rev. Psychol. 59, 255-278. doi: 10.1146/annurev.psych.59.103006.093629

Evans, J. S., and Stanovich, K. E. (2013). Dual-process theories of higher cognition: advancing the debate. Perspect. Psychol. Sci. 8, 223-241. doi: $10.1177 / 1745691612460685$

Fournier, M., d'Arripe-Longueville, F., and Radel, R. (2016). Testing the effect of text messaging cues to promote physical activity habits: a worksitebased exploratory intervention. Scand. J. Med. Sci. Sports 27, 1157-1165. doi: $10.1111 /$ sms. 12730

Fournier, M., Radel, R., Bailly, L., Pradier, C., Fabre, R., Fuch, A., et al. (2018). "As du Coeur" study: a randomized controlled trial on physical activity maintenance in cardiovascular patients. BMC Cardiovasc. Disord. 18:77. doi: 10.1186/s12872-018-0809-1

Fritz, H., Tarraf, W., Brody, A., and Levy, P. (2019). Feasibility of a behavioral automaticity intervention among African Americans at risk for metabolic syndrome. BMC Public Health 19:413. doi: 10.1186/s12889-019-6675-7

Gardner, B. (2015). A review and analysis of the use of 'habit' in understanding, predicting and influencing health-related behaviour. Health Psychol. Rev. 9, 277-295. doi: 10.1080/17437199.2013.876238

Gardner, B., de Bruijn, G. J., and Lally, P. (2011). A systematic review and meta-analysis of applications of the self-report habit index to nutrition and physical activity behaviours. Ann. Behav. Med. 42, 174-187. doi: 10.1007/s12160-011-9282-0
Gardner, B., and Lally, P. (2018). "Modelling habit formation and its determinants," in The Psychology of Habit, ed. P. Verplanken. Cham: Springer.

Gardner, B., Lally, P., and Rebar, A. L. (2020b). Does habit weaken the relationship between intention and behaviour? Revisiting the habit-intention interaction hypothesis. Soc. Person. Psychol. Compass. 14, 1-24. doi: 10.1111/spc3.12553

Gardner, B., Lally, P., and Wardle, J. (2012). Making health habitual: the psychology of 'habit-formation' and general practice. Br. J. Gen. Pract. 62, 664-666. doi: 10.3399/bjgp12X659466

Gardner, B., and Rebar, A. L. (2019). "Habit formation and behavior change," in Oxford Research Encyclopedia of Psychology. New York, NY: Oxford University Press.

Gardner, B., Rebar, A. L., and Lally, P. (2020a). 'Habitually deciding' or 'habitually doing'? A response to Hagger. Psychol. Sport Exerc. 47:101539. doi: 10.1016/j.psychsport.2019.05.008

Gardner, B., and Tang, V. (2014). Reflecting on non-reflective action: an exploratory think-aloud study of self-report habit measures. Br. J. Health Psychol. 19, 258-273. doi: 10.1111/bjhp.12060

Hagger, M. S. (2019). Habit and physical activity: theoretical advances, practical implications, and agenda for future research. Psychol. Sport Exerc. 42, 118-129. doi: 10.1016/j.psychsport.2018.12.007

Hagger, M. S. (2020). Redefining habits and linking habits with other implicit processes. Psychol. Sport Exerc. 46:101606. doi: 10.1016/j.psychsport.2019.101606

Hallal, P. C., Andersen, L. B., Bull, F. C., Guthold, R., Haskell, W., and Ekelund, U. (2012). Global physical activity levels: surveillance progress, pitfalls, and prospects. Lancet 380, 247-257. doi: 10.1016/S0140-6736(12)60646-1

Hamilton, K., Fraser, E., and Hannan, T. (2019). Habit-based workplace physical activity intervention: a pilot study. Occup. Med. 69, 471-474. doi: $10.1093 /$ occmed/kqz119

Howlett, N., Schulz, J., Trivedi, D., Troop, N., and Chater, A. (2019). A prospective study exploring the construct and predictive validity of the COM-B model for physical activity. J. Health Psychol. 24, 1378-1391. doi: $10.1177 / 1359105317739098$

Kahlert, D. (2015). Maintenance of physical activity: do we know what we are talking about? Prev. Med. Rep. 2, 178-180. doi: 10.1016/j.pmedr.2015.02.013

Kaushal, N., and Rhodes, R. E. (2015). Exercise habit formation in new gym members: a longitudinal study. J. Behav. Med. 38, 652-663. doi: 10.1007/s10865-015-9640-7

Kaushal, N., Rhodes, R. E., Meldrum, J. T., and Spence, J. C. (2017a). The role of habit in different phases of exercise. Br. J. Health Psychol. 22, 429-448. doi: 10.1111/bjhp.12237

Kaushal, N., Rhodes, R. E., Meldrum, J. T., and Spence, J. C. (2018). Mediating mechanisms in a physical activity intervention: a test of habit formation. J. Sport Exerc. Psychol. 40, 101-110. doi: 10.1123/jsep.2017-0307

Kaushal, N., Rhodes, R. E., Spence, J. C., and Meldrum, J. T. (2017b). Increasing physical activity through principles of habit formation in new gym members: a randomized controlled trial. Ann. Behav. Med. 51, 578-586. doi: 10.1007/s12160-017-9881-5

Kwasnicka, D., Dombrowski, S. U., White, M., and Sniehotta, F. (2016). Theoretical explanations for maintenance of behaviour change: a systematic review of behaviour theories. Health Psychol. Rev. 10, 277-296. doi: 10.1080/17437199.2016.1151372

Lally, P., Chipperfield, A., and Wardle, J. (2008). Healthy habits: efficacy of simple advice on weight control based on a habit-formation model. Int. J. Obes. 32, 700-707. doi: 10.1038/sj.ijo.0803771

Lally, P., and Gardner, B. (2013). Promoting habit formation. Health Psychol. Rev. 7, S137-S158. doi: 10.1080/17437199.2011.603640

Lally, P., van Jaarsveld, C. H. M., Potts, H. W. W., and Wardle, J. (2010). How are habits formed: Modelling habit formation in the real world. Eur. J. Soc. Psychol. 40, 998-1009. doi: 10.1002/ejsp.674

Liberati, A., Altman, D. G., Tetzlaff, J., Mulrow, C., Gotzsche, P. C., Ioannidis, J. P., et al. (2009). The PRISMA statement for reporting systematic reviews and meta-analyses of studies that evaluate health care interventions: explanation and elaboration. PLoS Med. 6:e1000100. doi: 10.1371/journal.pmed.1000100

Maddux, J. E. (1997). Haibt, health, and happiness. J. Sport Exerc. Psychol. 19, 331-346. doi: 10.1123/jsep.19.4.331

Marteau, T. M., Hollands, G. J., and Fletcher, P. C. (2012). Changing human behavior to prevent disease: the importance of targeting automatic processes. Science 337, 1492-1495. doi: 10.1126/science.1226918 
McEachan, R. R. C., Conner, M., Taylor, N. J., and Lawton, R. J. (2011). Prospective prediction of health-related behaviours with the Theory of Planned Behaviour: a meta-analysis. Health Psychol. Rev. 5, 97-144. doi: 10.1080/17437199.2010.521684

Michie, S., Richardson, M., Johnston, M., Abraham, C., Francis, J., Hardeman, W., et al. (2013). The behavior change technique taxonomy (v1) of 93 hierarchically clustered techniques: building an international consensus for the reporting of behavior change interventions. Ann. Behav. Med. 46, 81-95. doi: $10.1007 /$ s12160-013-9486-6

Mullan, B., Henderson, J., Kothe, E., Allom, V., Orbell, S., and Hamilton, K. (2016). The role of habit and perceived control on health behavior among pregnant women. Am. J. Health Behav. 40, 291-301. doi: 10.5993/AJHB.40.3.1

Musich, S., Wang, S. S., Hawkins, K., and Greame, C. (2017). The frequency and health benefits of physical activity for older adults. Popul. Health Manag. 20, 199-207. doi: 10.1089/pop.2016.0071

NHLBI (2014). Study Quality Assessment Tools. National Heart, Lung, and Blood Institute. Available: https://www.nhlbi.nih.gov/health-topics/studyquality-assessment-tools (accessed March 06, 2020).

Ogilvie, D., Bull, F., Cooper, A., Rutter, H., Adams, E., Brand, C., et al. (2012). Evaluating the travel, physical activity and carbon impacts of a 'natural experiment' in the provision of new walking and cycling infrastructure: methods for the core module of the iConnect study. BMJ Open 2:e000694. doi: 10.1136/bmjopen-2011-000694

Ogilvie, D., Bull, F., Powell, J., Cooper, A. R., Brand, C., Mutrie, N., et al. (2011). An applied ecological framework for evaluating infrastructure to promote walking and cycling: the iConnect study. Am. J. Public Health 101, 473-481. doi: 10.2105/AJPH.2010.198002

Peels, D. A., Bolman, C., Golsteijn, R. H., de Vries, H., Mudde, A. N., van Stralen, M. M., et al. (2013). Long-term efficacy of a printed or a Web-based tailored physical activity intervention among older adults. Int. J. Behav. Nutr. Phys. Act. 10:104. doi: 10.1186/1479-5868-10-104

Pfeffer, I., and Strobach, T. (2018). Behavioural automaticity moderates and mediates the relationship of trait self-control and physical activity behaviour. Psychol. Health 33, 925-940. doi: 10.1080/08870446.2018.1436176

Phillips, L. A., Chamberland, P. E., Hekler, E. B., Abrams, J., and Eisenberg, M. H. (2016). Intrinsic rewards predict exercise via behavioral intentions for initiators but via habit strength for maintainers. Sport Exerc. Perform. Psychol. 5, 352-364. doi: $10.1037 /$ spy0000071

Phillips, L. A., and Gardner, B. (2016). Habitual exercise instigation (vs. execution) predicts healthy adults' exercise frequency. Health Psychol. 35, 69-77. doi: 10.1037/hea0000249

Presseau, J., Johnston, M., Heponiemi, T., Elovainio, M., Francis, J. J., Eccles, M. P., et al. (2014). Reflective and automatic processes in health care professional behaviour: a dual process model tested across multiple behaviours. Ann. Behav. Med. 48, 347-358. doi: 10.1007/s12160-014-9609-8

Rebar, A. L., Dimmock, J. A., Jackson, B., Rhodes, R. E., Kates, A., Starling, J., et al. (2016). A systematic review of the effects of non-conscious regulatory processes in physical activity. Health Psychol. Rev. 10, 395-407. doi: 10.1080/17437199.2016.1183505

Rebar, A. L., Rhodes, R. E., and Gardner, B. (2019). How we are misinterpreting physical activity intention - behavior relations and what to do about it. Int. J. Behav. Nutr. Phys. Act. 16:71. doi: 10.1186/s12966-019-0829-y

Reiner, M., Niermann, C., Jekauc, D., and Woll, A. (2013). Long-term health benefits of physical activity-a systematic review of longitudinal studies. BMC Public Health 13:813. doi: 10.1186/1471-2458-13-813

Rhodes, R. E. (2017). "The evolving understanding of physical activity behavior," in Advances in Motivation Science, eds A. J. Elliot (Amsterdam: Elsevier Inc.), 171-205.

Rhodes, R. E., Blanchard, C. M., Quinlan, A., Naylor, P. J., and Warburton, D. E. R. (2019a). Family physical activity planning and child physical activity outcomes: a randomized trial. Am. J. Prev. Med. 57, 135-144. doi: 10.1016/j.amepre.2019.03.007

Rhodes, R. E., and Dickau, L. (2012). Experimental evidence for the intentionbehavior relationship in the physical activity domain: a meta-analysis. Health Psychol. 31, 724-727. doi: 10.1037/a0027290

Rhodes, R. E., Quinlan, A., Naylor, P. J., Warburton, D. E. R., and Blanchard, C. M. (2019b). Predicting personal physical activity of parents during participation in a family intervention targeting their children. J. Behav. Med. 43, 209-224. doi: 10.1007/s10865-019-00116-2

Schwarzer, R. (2008). Modeling health behavior change: how to predict and modify the adoption and maintenance of health behaviors. Appl. Psychol. 57, 1-29. doi: 10.1111/j.1464-0597.2007.00325.x

Schwarzer, R., Warner, L., Fleig, L., Gholami, M., Salvatore, S., Cianferotti, L., et al. (2017). Psychological mechanisms in a digital intervention to improve physical activity: a multicentre randomized controlled trial. Br. J. Health Psychol. 23, 296-310. doi: 10.1111/bjhp.12288

Sheeran, P., Gollwitzer, P. M., and Bargh, J. A. (2013). Nonconscious processes and health. Health Psychol. 32, 460-473. doi: 10.1037/a0029203

Strobach, T., Englert, C., Jekauc, D., and Pfeffer, I. (2020). Predicting adoption and maintenance of physical activity in the context of dual-process theories. Perform. Enhanc. Health. 8. doi: 10.1016/j.peh.2020.100162

Triandis, H. C. (1977). Interpersonal behavior. Monterey, CA: Brooks/Cole Pub. Co.

van Bree, R. J. H., Bolman, C., Mudde, A. N., Van Stralen, M. M., Peels, D. A., De Vries, H., et al. (2017). Modeling longitudinal relationships between habit and physical activity: two cross-lagged panel design studies in older adults. J. Aging Phys. Act. 25, 464-473. doi: 10.1123/japa.2016-0212

van Bree, R. J. H., Mudde, A. N., Bolman, C., van Stralen, M. M., Peels, D. A., de Vries, H., et al. (2016). Are action planning and physical activity mediators of the intention habit relationship? Psychol. Sport Exerc. 27, 243-251. doi: 10.1016/j.psychsport.2016.09.004

van Stralen, M. M., de Vries, H., Mudde, A. N., Bolman, C., and Lechner, L. (2011). The long-term efficacy of two computer-tailored physical activity interventions for older adults: Main effects and mediators. Health Psychol. 30, 442-452. doi: $10.1037 / \mathrm{a} 0023579$

Wallmann-Sperlich, B., Hoffmann, S., Salditt, A., Bipp, T., and Froboese, I. (2019). Moving to an "Active" biophilic designed office workplace: a pilot study about the effects on sitting time and sitting habits of office-based workers. Int. J. Environ. Res. Public Health 16, 1-13. doi: 10.3390/ijerph16091559

Walter, N. (2017). Verhaltensstabilität und gewohnheitsverhalten. Präv. Gesundheitsförderung 13, 123-130. doi: 10.1007/s11553-017-0625-y

Warburton, D. E. R., and Bredin, S. S. D. (2017). Health benefits of physical activity: a systematic review of current systematic reviews. Curr. Opin. Cardiol. 32, 541-556. doi: 10.1097/HCO.00000000000 00437

Weyland, S., Finne, E., Krell-Roesch, J., and Jekauc, D. (2020). (How) Does affect influence the formation of habits in exercise? Front. Psychol. 11:578108. doi: 10.3389/fpsyg.2020.578108

White, I., Smith, L., Aggio, D., Shankar, S., Begum, S., Matei, R., et al. (2017). On your feet to earn your seat: pilot RCT of a theory-based sedentary behaviour reduction intervention for older adults. Pilot Feas. Stud. 3:23. doi: 10.1186/s40814-017-0139-6

White, R. L., Babic, M. J., Parker, P. D., Lubans, D. R., Astell-Burt, T., and Lonsdale, C. (2017). Domain-specific physical activity and mental health: a meta-analysis. Am. J. Prev. Med. 52, 653-666. doi: 10.1016/j.amepre.2016. 12.008

WHO (2010). Global Recommendations on Physical Activity for Health. Geneva: World Health Organization.

WHO (2020). Global Strategy on Diet, Physical Activity and Health. World Health Organization. Available online at: https://www.who.int/dietphysicalactivity/ pa/en/\#: :text=Physical\%20activity\%20is\%20defined\%20as, 6\%25\%20of \%20deaths\%20globally (accessed March 06, 2020).

Conflict of Interest: The authors declare that the research was conducted in the absence of any commercial or financial relationships that could be construed as a potential conflict of interest.

Copyright (C) 2021 Feil, Allion, Weyland and Jekauc. This is an open-access article distributed under the terms of the Creative Commons Attribution License (CC BY). The use, distribution or reproduction in other forums is permitted, provided the original author(s) and the copyright owner(s) are credited and that the original publication in this journal is cited, in accordance with accepted academic practice. No use, distribution or reproduction is permitted which does not comply with these terms. 